\title{
A new species of trionychid turtle, Axestemys infernalis sp. nov., from the Late Cretaceous (Maastrichtian) Hell Creek and Lance formations of the Northern Great Plains, USA
}

\author{
Walter G. Joyce, Donald B. Brinkman, and Tyler R. Lyson
}

\begin{abstract}
The Late Cretaceous (Maastrichtian) Hell Creek and Lance formations in the states of North Dakota, South Dakota, Montana, and Wyoming, USA, have yielded rich remains of trionychid turtles, but the alpha taxonomy of the group is still poorly resolved, as most fossils are fragmentary. We here describe a new species of trionychid, Axestemys infernalis sp. nov., based on a rich assortment of skulls, shells, and postcranial remains collected from nine fossiliferous sites spread throughout these formations. The new species is attributable to the Axestemys lineage based on the combined presence of large size, a preneural, and a single lateral hyoplastral process. Axestemys infernalis sp. nov. differs from all Paleogene representatives of Axestemys by lacking elongate free ribs and by possessing costal sculpturing that reaches the margin of the shell. It further differs from the only other Mesozoic representative of the lineage, Axestemys splendidus, a species herein restricted to the Campanian, by possessing a rounded carapace. The available Axestemys infernalis sp. nov. material shows much variation, in particular in regards to the maximum size of individuals and the relative size of callosities, but not enough to warrant recognizing multiple species. Instead, this variation is likely caused by random drift or phenotypic variation that accrued over the course of the approximately 1.36 Ma represented in the Hell Creek Formation.
\end{abstract}

Walter G. Joyce. Departement für Geowissenschaften, Universität Freiburg, 1700 Freiburg, Switzerland. walter.joyce@unifr.ch Donald Brinkman. Royal Tyrell Museum of Palaeontology, Box 7500, Drumheller, Alberta, Canada and Department of Biological Sciences, University of Alberta, T6G 2E9, Edmonton, Alberta, Canada. Don.Brinkman@gov.ab.ca Tyler R. Lyson, Department of Earth Sciences, Denver Museum of Nature Science, Denver, Colorado 80205, USA. Tyler.Lyson@dmns.org

http://zoobank.org/4A03186A-B787-43CC-81E6-B8F14E030243

Joyce, Walter G., Brinkman, Donald B., and Lyson, Tyler R. 2019. A new species of trionychid turtle, Axestemys infernalis sp. nov., from the Late Cretaceous (Maastrichtian) Hell Creek and Lance formations of the Northern Great Plains, USA. Palaeontologia Electronica 22.3.72 1-28. https://doi.org/10.26879/949

palaeo-electronica.org/content/2019/2827-a-new-species-of-trionychid

Copyright: November 2019 Paleontological Society.

This is an open access article distributed under the terms of Attribution-NonCommercial-ShareAlike 4.0 International (CC BY-NC-SA 4.0 ), which permits users to copy and redistribute the material in any medium or format, provided it is not used for commercial purposes and the original author and source are credited, with indications if any changes are made.

creativecommons.org/licenses/by-nc-sa/4.0/ 
Keywords: Testudines; Trionychidae; Trionychinae; morphology; phylogeny; paleobiodiversity; new species

Submission: 4 December 2018. Acceptance: 15 October 2019.

\section{INTRODUCTION}

The coeval Late Cretaceous (Maastrichtian) Hell Creek and Lance formations are broadly exposed across the Upper Great Plains of the states of North Dakota, South Dakota, Montana, and Wyoming, USA (Figure 1). Over the course of the last two centuries, these formations have yielded exceptionally diverse fauna and flora that have provided rich insights into a continental ecosystem prior to the Cretaceous/Paleogene (K/Pg) extinction event (see Hartman et al., 2002 and Wilson et al., 2014 for recent summaries). The Hell Creek and Lance turtle fauna is particularly diverse and consists of nearly two dozen species of adocids, chelydroids, nanhsiungchelyids, paracryptodires, and trionychids (e.g., Riggs, 1906; Hay, 1908; Case, 1939; Gaffney, 1972; Whetstone, 1978; Meylan and Gaffney, 1989; Holroyd and Hutchison, 2002; Lyson and Joyce, 2009a, b, 2010; Knauss et al., 2011; Lyson and Joyce, 2011; Lyson et al., 2011; Holroyd et al., 2014). Trionychid turtles have been a particularly difficult group to disentangle at the alpha taxonomic level, as frag- ments are common, but more complete remains are rare. In addition, both extant (Meylan, 1987) and fossil (Gardner and Russell, 1994) trionychids exhibit a high degree of morphological plasticity. In an initial review of the fauna, Hutchison and Archibald (1986) concluded that nine trionychids can be distinguished using shell fragments, of which four were thought to be trionychines (i.e., non-plastomenid trionychids). No trionychine was identified to the species level in this study. Using a similar approach, Holroyd and Hutchison (2002) later arrived at a more conservative estimate of six trionychids, of which three were thought to be trionychines, including unidentified representatives of the Apalone and "Aspideretes" lineages.

Joyce and Lyson (2011) more recently identified fossils of Gilmoremys lancensis (Gilmore, 1916) from the Hell Creek Formation, a taxon which had initially been described from the coeval Lance Formation of Wyoming. Although the skull of this taxon shows clear affinities with plastomenids, the shell plesiomorphically resembles trionychines by lacking extensive plastral callosities (Joyce and Lyson, 2011). Vitek (2012) concluded that particu-

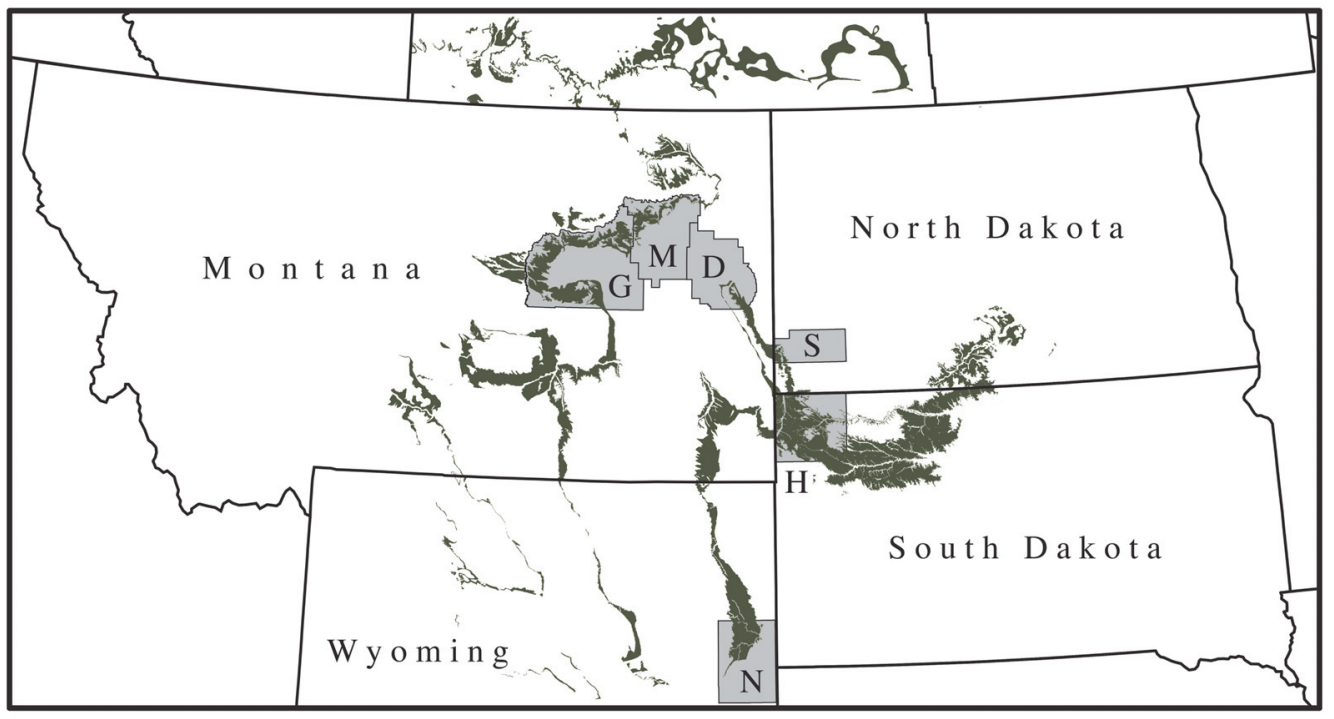

FIGURE 1. Simplified map of Montana, North Dakota, South Dakota, and Wyoming, USA, illustrating the known county distribution of Axestemys infernalis sp. nov. in the Late Cretaceous (Maastrichtian) Hell Creek and Lance formations. Outcrops of the Hell Creek and stratigraphically equivalent Lance Creek, Scollard, and Frenchman formations are highlighted in grey. Abbreviations: $D=$ Dawson County; $G=$ Garfield County; $H=$ Harding County; $M=$ McCone County; $\mathrm{N}=$ Niobrara County; $\mathrm{S}=$ Slope County. 
larly large trionychid remains from the Hell Creek formation are attributable to the giant softshell turtle Axestemys splendidus (Hay, 1908), which was originally identified from Late Cretaceous (Campanian) sediments exposed in Alberta, Canada, and Montana, USA. These taxa likely represent two of the trionychines identified by Hutchison and Archibald (1986) and Holroyd and Hutchison (2002).

We present an expanded sample of material referable to Axestemys that further clarifies the taxonomy of this giant trionychid. Although our analysis confirms previously noted similarities between Campanian and Maastrichtian representatives of the lineage (Vitek, 2012), we conclude that all Axestemys material from the Hell Creek and Lance represents a new species, which we name Axestemys infernalis sp. nov. The phylogenetic relationships of this taxon will be explored elsewhere.

\section{Institutional Abbreviations}

AMNH = American Museum of Natural History, New York, New York, USA; DMNH = Denver Museum of Nature and Science, Denver, Colorado, USA; FHSM = Sternberg Museum of Natural History, Fort Hays State University, Hays, Kansas, USA; LACM = Natural History Museum of Los Angeles, Los Angeles, California, USA; NSM = National Museum of Nature and Science, Tokyo, Japan; RAM = Raymond M. Alf Museum of Paleontology, Claremont, California, USA; TMP = Tyrell Museum of Paleontology, Drumheller, Alberta, Canada; UALVP = University of Alberta Laboratory for Vertebrate Paleontology.

\section{MATERIALS}

In this paper, we make use of a rich collection of Axestemys infernalis sp. nov. material that has been assembled by numerous institutions over the course of the last century from outcrops of the Hell Creek and Lance formations across the states of Montana, North Dakota, South Dakota, and Wyoming (Figure 1). More detailed information regarding all localities can be acquired from the relevant institutions.

\section{Turtle Bonebed}

This locality in Harding County, South Dakota, yielded the remains of more than 10 disarticulated individuals of the new trionychid species spread across a few square meters and embedded in a fine-grained matrix interpreted as a low energy environment. Individuals range in size from small (carapace length ca. $15 \mathrm{~cm}$ ) to intermediate (cara- pace length ca. $40 \mathrm{~cm}$ ). With the exception of some carapaces and some hyo/hypoplastra, all remains are disarticulated, and it is therefore not possible to refer elements to a particular individual. In addition, while shell and long bone remains abound, small bones are rare (e.g., phalanges and vertebrae), and skulls are absent. A number of skeletal specimens were removed from the field in jackets, but much has been left in situ. Given the extreme richness of this locality, we restrict ourselves to figuring representative material that has been removed from the blocks (Figures 2, 3, 4, 5, 6). An isolated baenid skull referable to a new species of baenid is the only accompanying fossil from this site. The Turtle Bonebed locality was discovered and quarried by a commercial enterprise on private land, but the fossils were prepared at TMP following their acquisition.

\section{Big Turtle Cove}

The Big Turtle Cove in Slope County, North Dakota, is located at the base of the Hell Creek Formation, 64-74 $\mathrm{m}$ below the formational contact. The locality yielded the partially disarticulated remains of at least three large individuals of the new species (carapace length up to $70 \mathrm{~cm}$ ). All were found in a coarse-grained sandstone rich in approximately $1 \mathrm{~cm}$ large rip up clasts interpreted as a channel lag deposit. In addition to shell remains, the locality has yielded a cranium, a mandible, a pelvis, and large limb bones (Figures 7, 8, 9 ). Although the remains were strewn across many square meters, the small number of individuals allows tentatively referring the largest material to the same individual. The quarry has otherwise yielded a cranium of the baenid Eubaena cephalica Hay, 1904 (Rollot et al., 2018), an undescribed cranium of the baenid Plesiobaena brinkman Lyson and Joyce, 2009b, disarticulated baenid shell material, lower jaws and isolated vertebrae and ribs of the choristoderan Champsosaurus sp., and elements of the dinosaur Thescelosaurus sp. Some trionychid remains from the Big Turtle Cove were previously figured and described by Vitek (2012, figures $9,10,11,12$ ), but further preparation and the discovery of additional material, in particular a well-preserved shell and cranium, warrants redescription of all material.

\section{Turtle Ridge}

The Turtle Ridge locality is located near the base of the Hell Creek Formation, 56.47-58.68 m below the Hell Creek/Fort Union formational contact in Slope County, North Dakota. In contrast to 
the other localities discussed herein, the Turtle Ridge unites numerous small quarries that are scattered across $400 \mathrm{~m}$, but all remains originate from a single horizon consisting of coarse-grained sandstone rich in $1-2 \mathrm{~cm}$ sized clay clasts that is interpreted as a channel lag deposit (Lyson and Joyce, 2010). In addition to fish and crocodylian remains, this locality yielded the holotype of the baenid Gammerabaena sonsalla Lyson and Joyce, 2010 , rich material of a new baenid, a partial cranium of a possible chelydroid (DMNH 130940), a previously undescribed hyo/hypoplastron of the plastomenid Gilmoremys lancensis (DMNH 98785), a shell and partial plastron provisionally identified as "Trionyx" beecheri Hay, 1904, a previously figured and described skull of Axestemys infernalis sp. nov. (Vitek, 2012, figure 8), and a rich assortment of disarticulated shell material of at least three individuals here referred to Axestemys infernalis sp. nov. (Figure 10). These individuals range in size from intermediate (carapace length ca. $40 \mathrm{~cm}$ ) to large (carapace length ca. $60 \mathrm{~cm}$ ). Taphonomic sorting is apparent at this locality, as limb remains and vertebrae are absent.

\section{Turtle Graveyard}

The Turtle Graveyard is stratigraphically equivalent to the nearby (approximately $400 \mathrm{~m}$ ) Turtle Ridge locality in Slope County, North Dakota, but documents a separate depositional event. The single sandstone horizon exposed in the quarry has yielded an exceptionally high abundance of fossil remains that are interpreted as having accumulated as the result of a severe drought. In addition to isolated remains of fish, crocodylians, and theropod dinosaurs, the locality has produced the holotype and referred material of the baenid Palatobaena cohen Lyson and Joyce, 2009a, dozens of shells and skulls of an undescribed new species of baenid, several shells and skulls of the plastomenid Gilmoremys lancensis (Joyce and Lyson, 2011), and the disarticulated shell remains and the mandible of at least two medium-sized individuals (carapace length about $40 \mathrm{~cm}$ ) here referred to Axestemys infernalis sp. nov. (Figures 11, 12).

\section{AMNH 14149}

This large (carapace length about $60 \mathrm{~cm}$ ) previously unpublished partial carapace (Figure 13) was collected in 1970 by Eugene Gaffney from a claystone at the top of a butte within the confines of Makoshika State Park in Dawson County, Mon- tana. This find does not include any accompanying fauna.

\section{LACM 15432}

LACM 15432 represents the exceptionally well-preserved anterior half of a large carapace (carapace length about $60 \mathrm{~cm}$ ) that was collected in 1965 by H.J. Garbani in Garfield County, Montana (Figure 14). This isolated find is not associated with any other fossils.

\section{RAM V94269}

RAM locality V94269 in McCone County, Montana, yielded a well-preserved, slightly crushed carapace (RAM 9393, Figure 15) that we refer to Axestemys infernalis sp. nov. The specimen was recovered about $3 \mathrm{~m}$ below the lowest $Z$ coal and therefore can be interpreted as being from the latest Maastrichtian portion of the upper third of the Hell Creek Formation.

\section{Sandy Site}

The Sandy Site was discovered by a private enterprise on private land in Harding County, South Dakota. The majority of fossils from this locality were sold to NSM following preparation. Although the quarry has yielded thousands of well-preserved bones that document dozens of fish, dinosaur, mammals, and reptile taxa (Triebold, 1997; Bartlett, 2004), only some dinosaur remains have been published formally (Russell and Manabe, 2002). The turtle fauna (pers. obs. of material at NSM) includes remains referable to the adocusians Adocus lineolatus Cope, 1874, and Basilemys sinuosa Riggs, 1906, the paracryptodire Compsemys victa Leidy, 1856, and the macrobaenid Judithemys sp. Numerous shell fragments document unnamed chelydroids. Baenids are represented by numerous indeterminate fragments, but also several shells and skull of an indeterminate eubaenine. The trionychid fauna finally includes specimens referable to Hutchemys sterea (Hutchison, 2009), Atoposemys superstes (Russell, 1930), and a partial skull and several plastral remains of at least two individuals here referred to Axestemys infernalis sp. nov. (Figure 16).

\section{FHSM VP200}

FHSM VP200 is a historic specimen (Figure 17) that was collected in 1930 by G.F. Sternberg from outcrops of the Lance Formation "W. of Warren" (as stated on the museum label) in Niobrara County, Wyoming. Although we are unable to locate a place named Warren, the Lance Forma- 
tion is broadly exposed in Niobrara County. No fauna is known to accompany this fossil and complete preparation of the specimen precludes assessment of the depositional environment.

\section{SYSTEMATIC PALEONTOLOGY}

TESTUDINES Batsch, 1788

CRYPTODIRA Cope, 1868

TRIONYCHIDAE Gray, 1825

TRIONYCHINAE Nopcsa, 1928

AXESTEMYS Hay, 1899

Axestemys infernalis sp. nov.

Figures 2, 3, 4, 5, 6, 7, 8, 9, 10, 11, 12, 13, 14, 15, $16,17,18,19$

zoobank.org/A09F6604-BCEF-4CB1-A382-2F1CFD8C25D8

1

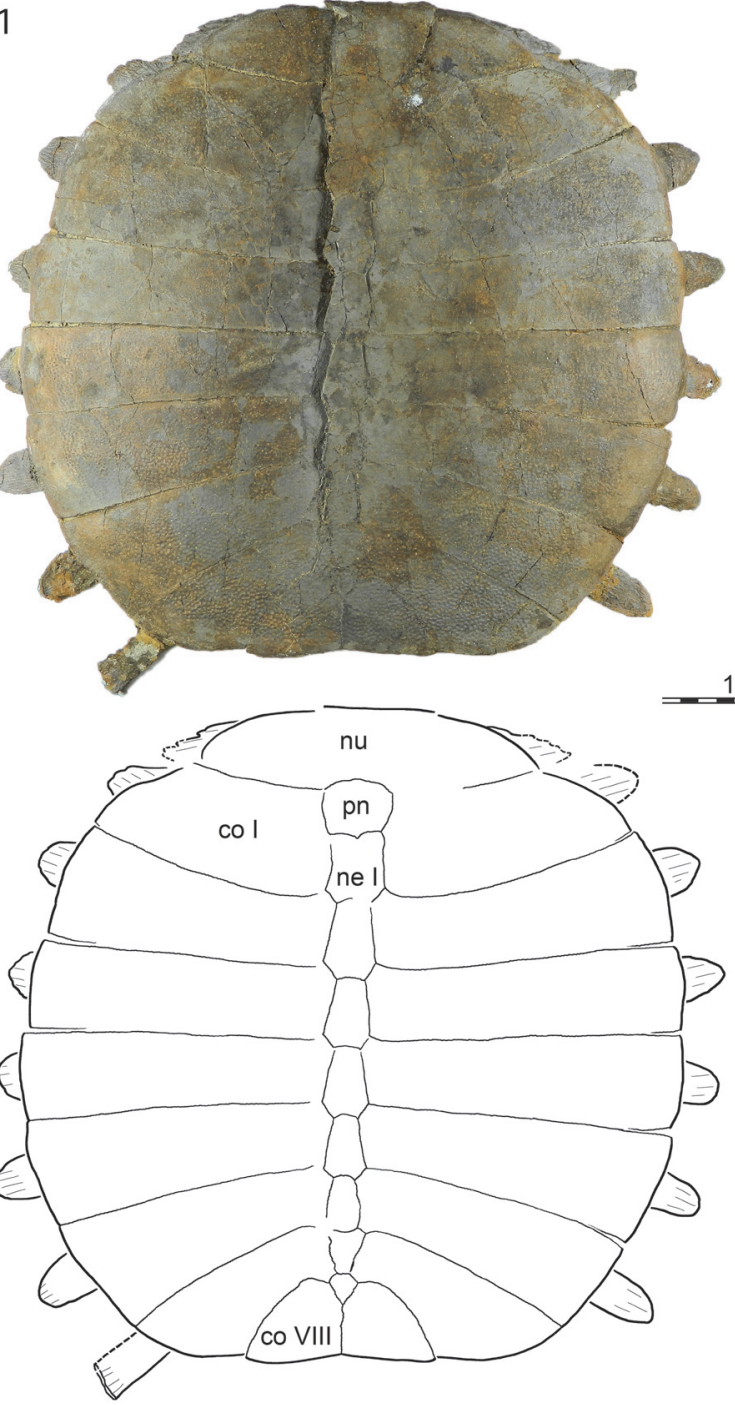

\section{Holotype}

DMNH 131100, a near-complete carapace (Figures 7.1, 8.1).

\section{Type Locality and Horizon}

Big Turtle Cove locality, Slope County, North Dakota, USA; lower Hell Creek Formation, 64-74 m below the formational contact with the overlying Fort Union Formation, Late Cretaceous (Maastrichtian) (see Materials above for more details). The exact location of the locality is held on file at $\mathrm{DMNH}$ and will be provided to qualified researchers upon request.
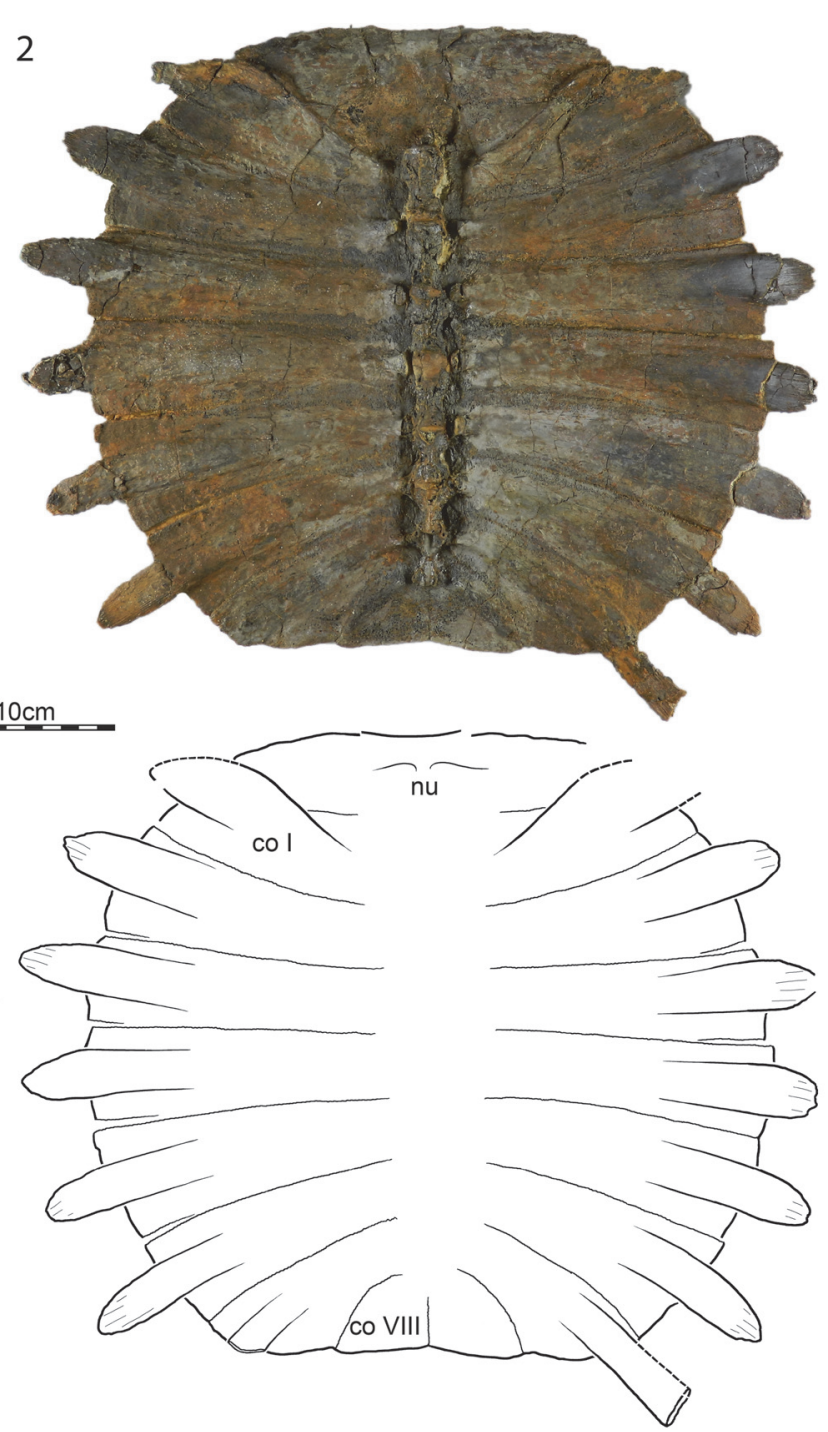

FIGURE 2. Axestemys infernalis sp. nov. from the Late Cretaceous (Maastrichtian) Turtle Bonebed locality of Harding County, South Dakota, USA. Photograph and line drawings of TMP 2009.24.10, a carapace, in (1) dorsal and (2) ventral views. Abbreviations: $c o=$ costal; ne $=$ neural; $n u=$ nuchal; $p n=$ preneural. 
1
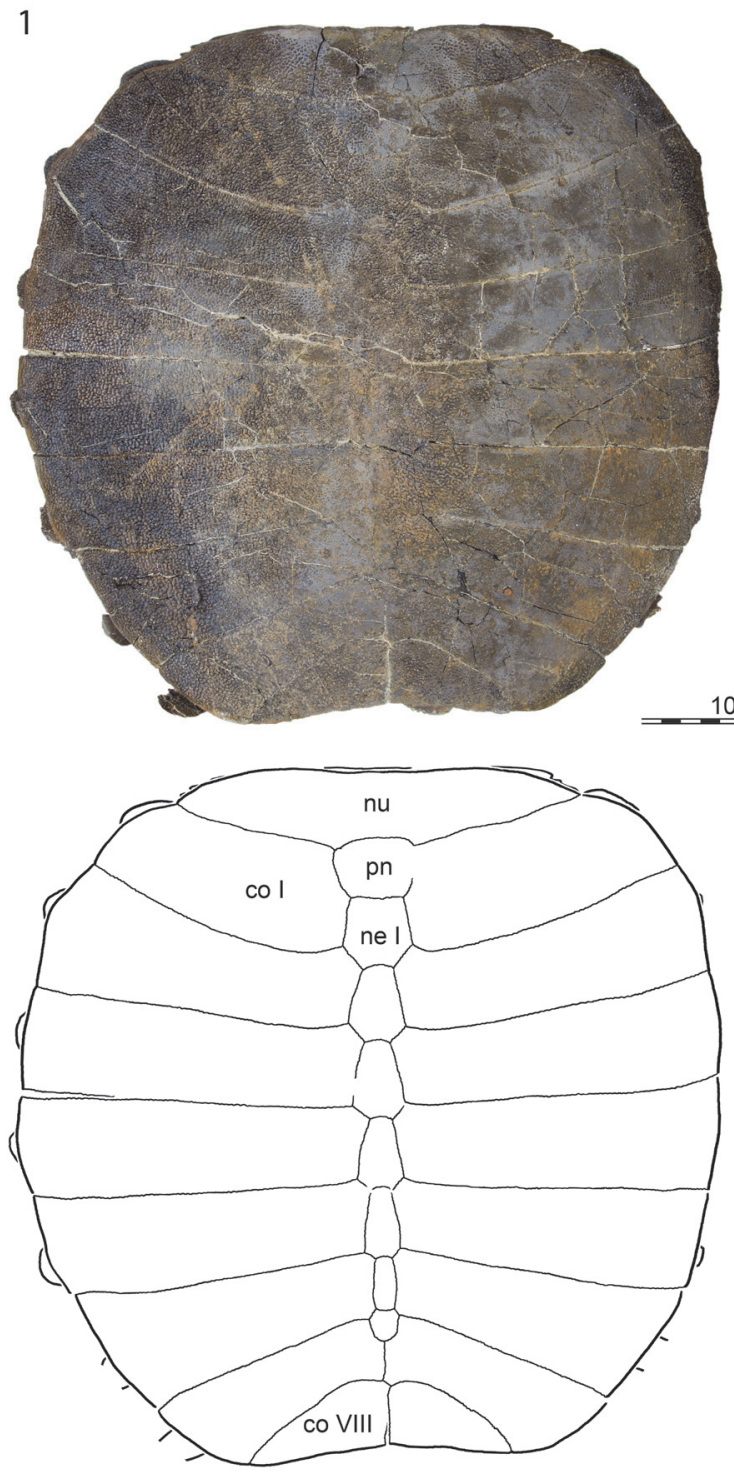

2
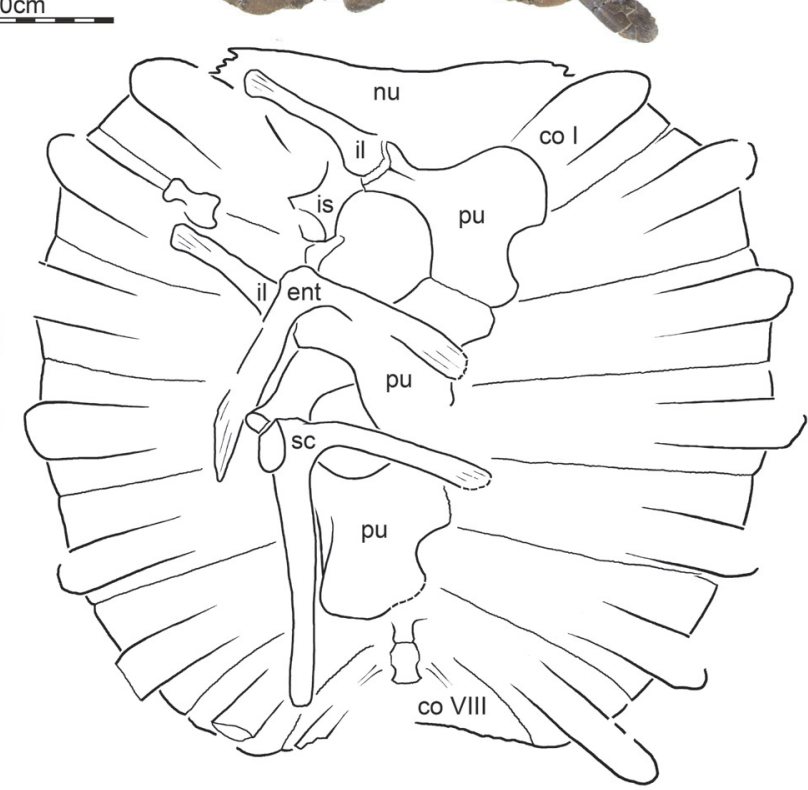

FIGURE 3. Axestemys infernalis sp. nov. from the Late Cretaceous (Maastrichtian) Turtle Bonebed locality of Harding County, South Dakota, USA. Photograph and line drawings of TMP 2009.24.137, a carapace, in (1) dorsal and (2) ventral views. Abbreviations: $c o=$ costal; ent = entoplastron; il = ilium; is = ischium; ne = neural; nu = nuchal; $p u=$ pubis; $p n=$ preneural; $\mathrm{sc}=$ scapula .

\section{Referred Material and Range}

Late Cretaceous (Maastrichtian) Hell Creek and Lance formations, Montana, North Dakota, South Dakota, and Wyoming, USA (referred material of Vitek, 2012 and all specimens listed in the Materials herein).

\section{Etymology}

The species epithet infernalis, Latin for hellish, is here chosen in reference to the Hell Creek Formation.

\section{Diagnosis}

Among trionychids from the Late Cretaceous to Paleogene of North America, Axestemys infernalis sp. nov. can be diagnosed as a representative of Axestemys by the unique combination of the plesiomorphic presence of a preneural in combination with the apomorphic development of large size and the presence of a single lateral hyoplastral process. Axestemys infernalis sp. nov. resembles Axestemys splendidus, but differs from all Paleogene representatives of Axestemys, by the absence of elongate free ribs and by possessing 

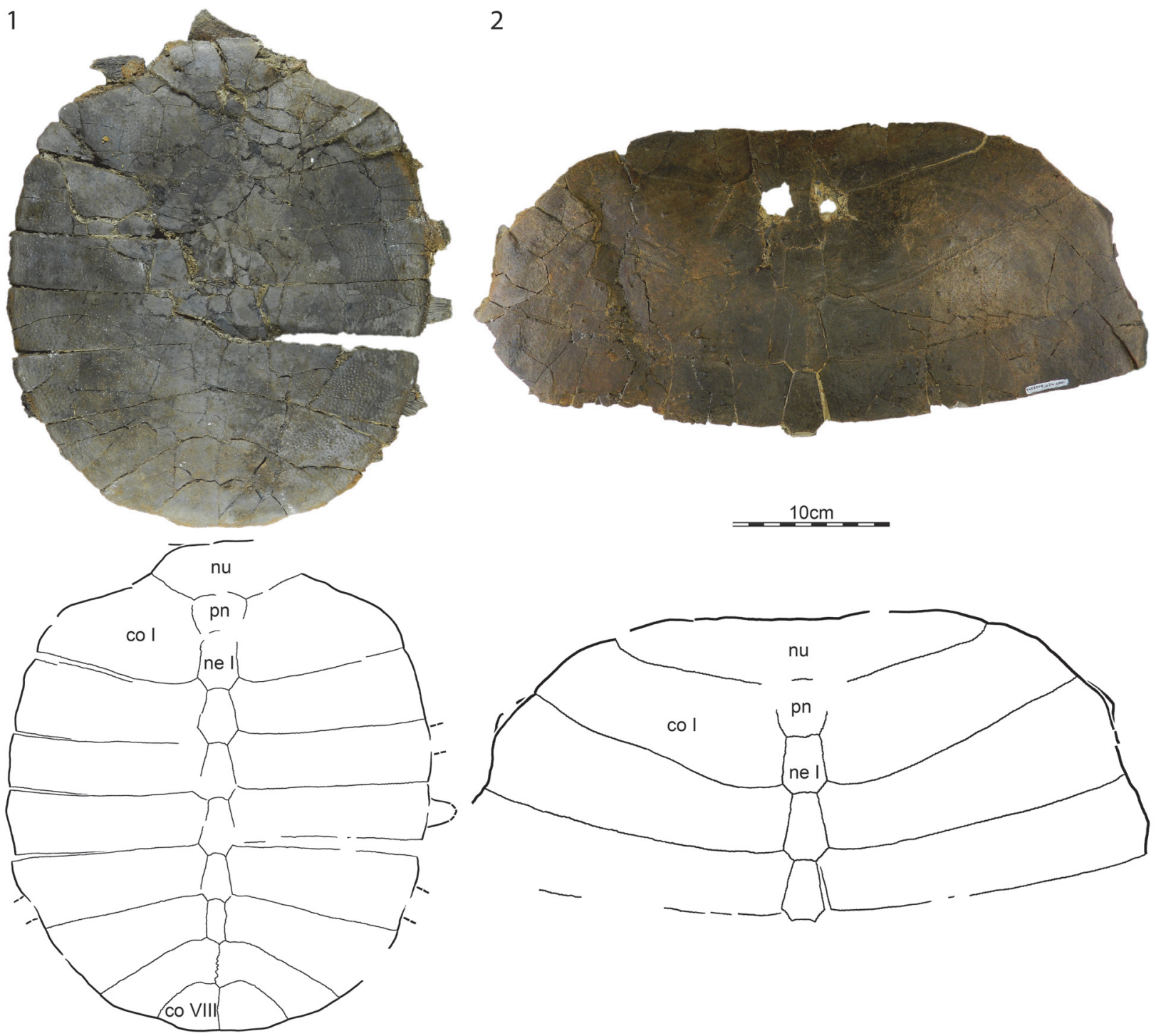

FIGURE 4. Axestemys infernalis sp. nov. from the Late Cretaceous (Maastrichtian) Turtle Bonebed locality of Harding County, South Dakota, USA. Photograph and line drawings of (1) TMP 2009.24.4, a carapace, and (2) TMP 2009.24.105, a partial carapace, in dorsal view. Abbreviations: $c o=$ costal; ne $=$ neural; $n u=$ nuchal; $p n=$ preneural.

costal sculpturing that reaches the margin of the shell. Axestemys infernalis sp. nov. differs from Axestemys splendidus by having a rounded carapace, instead of a disk that is notably wider than long.

\section{Comment}

We select DMNH 131100 as the holotype of Axestemys infernalis sp. nov., as this carapace displays the greatest number of characters that we find to be diagnostic of this taxon: large size, a rounded carapacial disk, presence of a preneural, absence of elongate free ribs, and costal sculpturing that reaches the margin of the shell. This shell from the Big Turtle Cove locality is closely associated with plastral remains that document the remaining characters diagnostic of this taxon. We purposefully refrained from selecting a cranium, as we are unable to find diagnostic characters in this part of the system.

\section{Description}

Carapace. The remains of at least 14 carapaces are available for study, of which five are complete with the exception of broken rib ends (Figures 2, 3, $4.1,7.1,9.1,15)$. The carapace generally consists of a nuchal, eight pairs of costals, a preneural, and six to eight neurals, and ranges in size from 


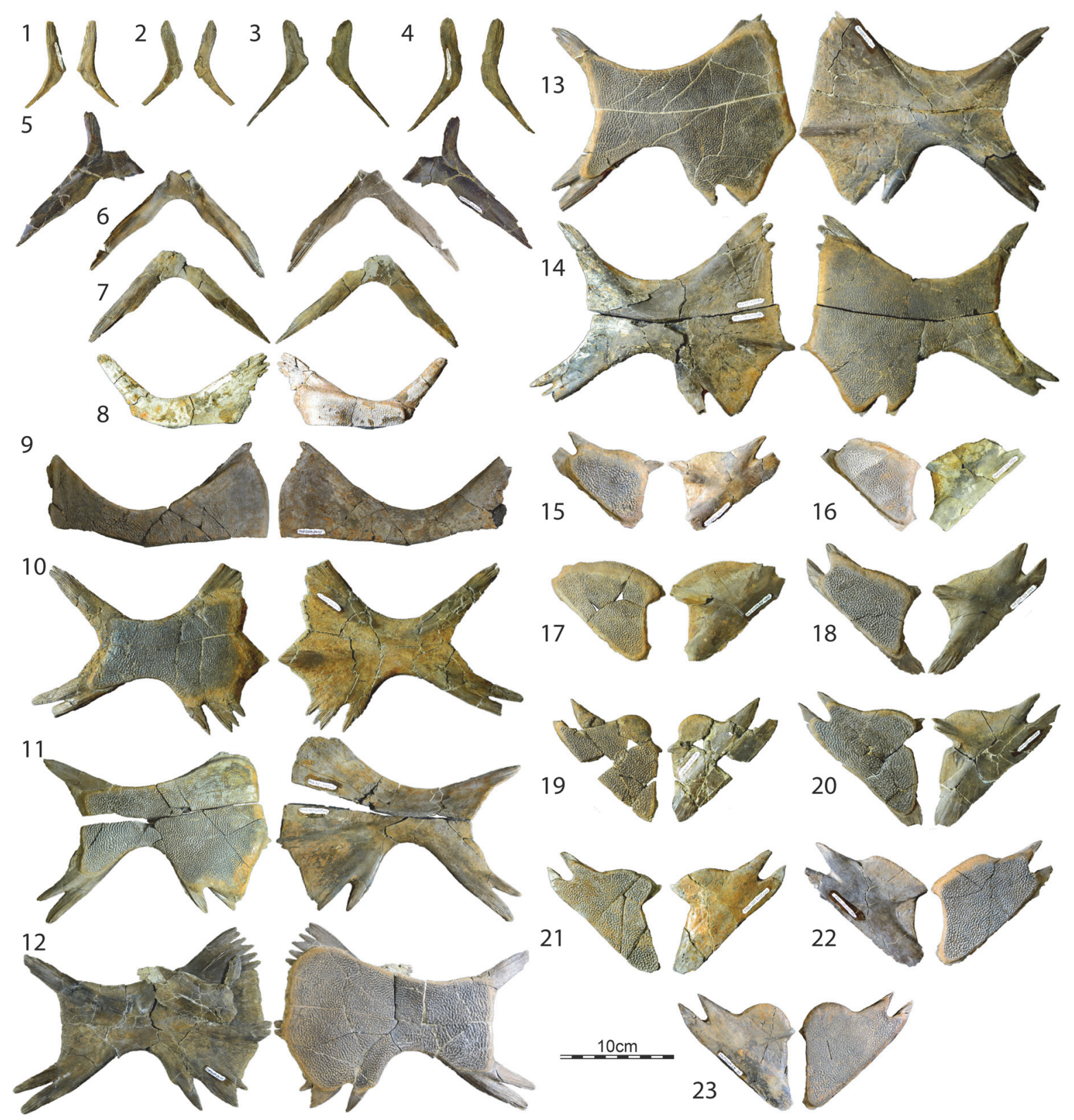

FIGURE 5. Axestemys infernalis sp. nov. from the Late Cretaceous (Maastrichtian) Turtle Bonebed locality of Harding County, South Dakota, USA. Photographs of (1) TMP 2009.24.75, right epiplastron, in ventral and dorsal views; (2) TMP 2009.24.73, right epiplastron, in ventral and dorsal views; (3) TMP 2009.24.72, right epiplastron, in ventral and dorsal views; (4) TMP 2009.24.16, right epiplastron, in ventral and dorsal views; (5) TMP 2009.24.51, left epiplastron and entoplastron, in dorsal and ventral views; (6) TMP 2009.24.52, entoplastron, in dorsal and ventral views; (7) TMP 2009.24.56, entoplastron, in dorsal and ventral views; (8) TMP 2009.24.93, left hyoplastron, in dorsal and ventral views; (9) TMP 2009.24.97, right hyoplastron, in ventral and dorsal views; (10) TMP 2009.24.98, right hyo/hypoplastron, in ventral and dorsal views; (11) TMP 2009.24.44, right hyo/hypoplastron, in ventral and dorsal views; (12) TMP 2009.24.95, left hyo/hypoplastron, in dorsal and ventral views; (13) TMP 2009.24.101, right hyo/hypoplastron, in ventral and dorsal views; (14) TMP 2009.24.48, left hyo/hypoplastron, in dorsal and ventral views; (15) TMP 2009.24.80, right xiphiplastron, in ventral and dorsal views; (16) TMP 2009.24.54, right xiphiplastron, in ventral and dorsal views; (17) TMP 2009.24.55, right xiphiplastron, in ventral and dorsal views; (18) TMP 2009.24.47, right xiphiplastron, in ventral and dorsal views; (19) TMP 2009.24.125, right xiphiplastron, in ventral and dorsal views; (20) TMP 2009.24.43, right xiphiplastron, in ventral and dorsal views; (21) TMP 2009.24.46, right xiphiplastron, in ventral and dorsal views; (22) TMP 2009.24.42, left xiphiplastron, in dorsal and ventral views; (23) TMP 2009.24.81, left xiphiplastron, in dorsal and ventral views. See Figure 6 for line drawings of these specimens. 

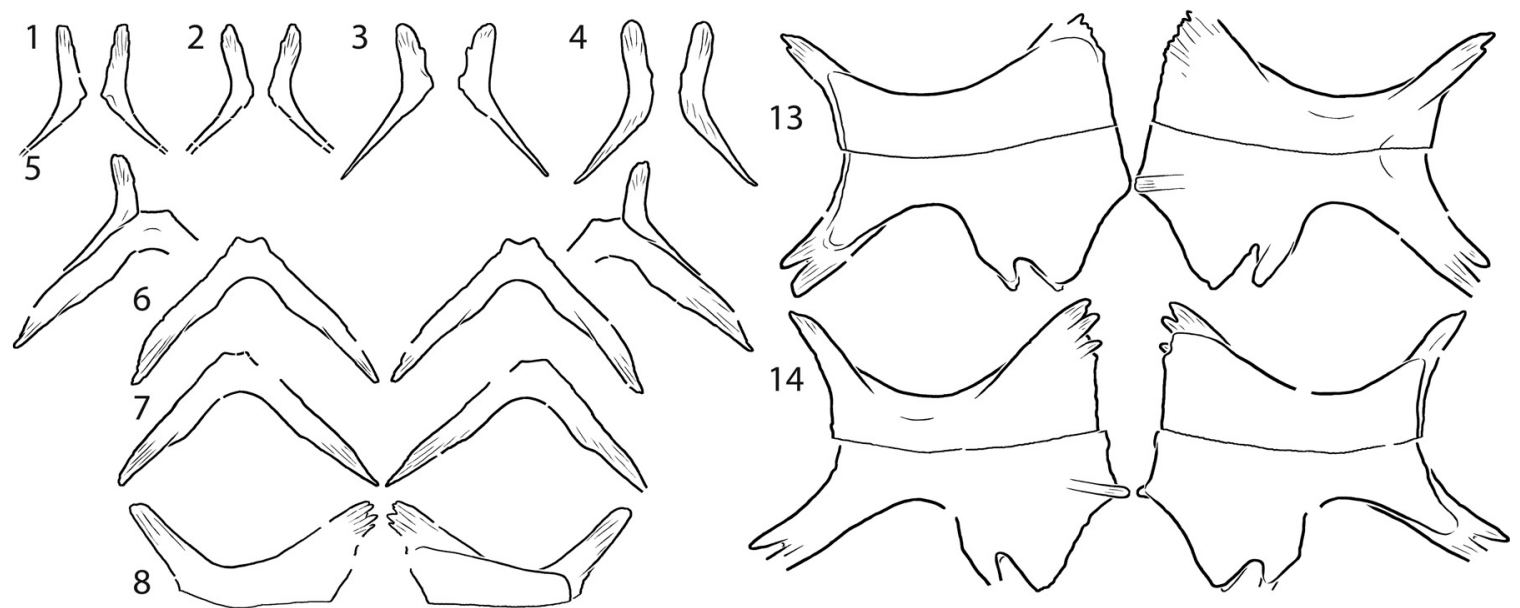

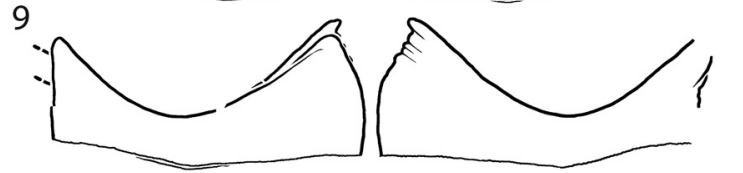

9
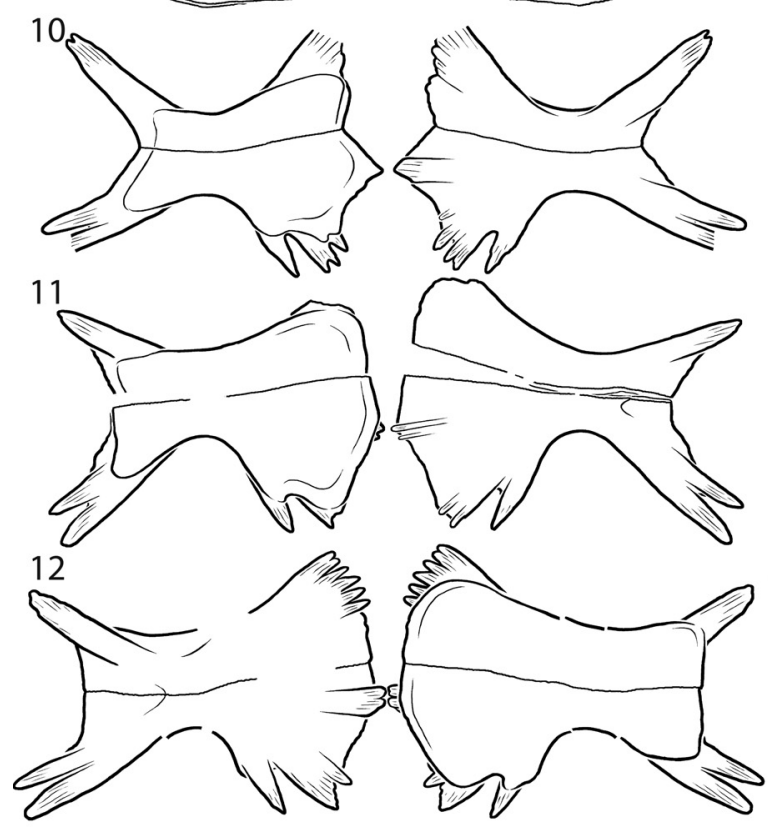

15
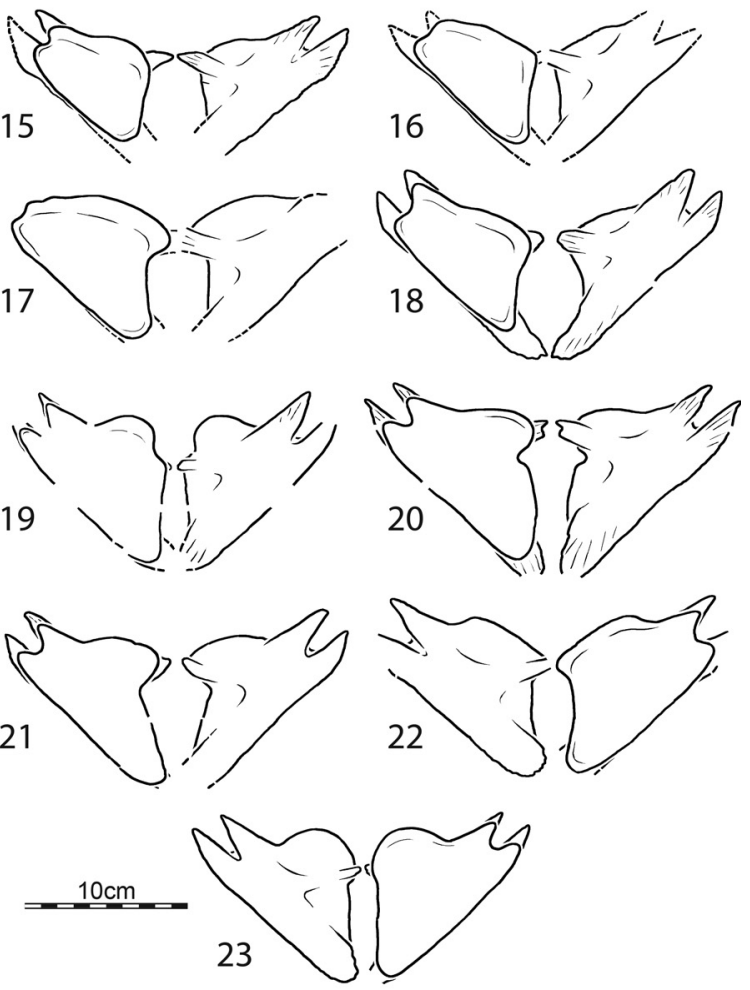

FIGURE 6. Axestemys infernalis sp. nov. from the Late Cretaceous (Maastrichtian) Turtle Bonebed locality of Harding County, South Dakota, USA. Line drawings of specimens depicted in Figure 5.

approximately 40 to $60 \mathrm{~cm}$. The carapacial disk is rounded and the ribs protrude from the distal margins of all costals, even in the largest available specimens (Figure 7.1). The carapacial callosities are fully covered by surficial sculpturing. Sculpturing varies from closely netted (e.g., Figure 7.6) to an indistinct pattern consisting of unconnected tubercles and ridges (e.g., Figure 14). In larger individuals, sculpturing is often lacking along the intercostal sutures (e.g., Figure 14). Sculpturing is worn to absent in many individuals from the Turtle Bonebed locality (Figures 2, 3, 4) and some speci- mens have a pitted (e.g., Figure 4.1) or completely smooth surface texture (e.g., Figure 4.2), but we interpret this as a taphonomic artifact, as wear is patchy and asymmetric.

Nuchal. A total of 13 nuchals are available that range in size (Figures 2, 3, 4, 7, 8, 9, 10, 11, 12, $13,14,15)$. The nuchal possesses a dense comb of lateral processes that splay out distally to form a bow-shaped element. The relative size of the nuchal callosities varies among the available specimens. At its smallest (e.g., Figure 10.1), the nuchal callosity forms a small, semi-lunate protru- 


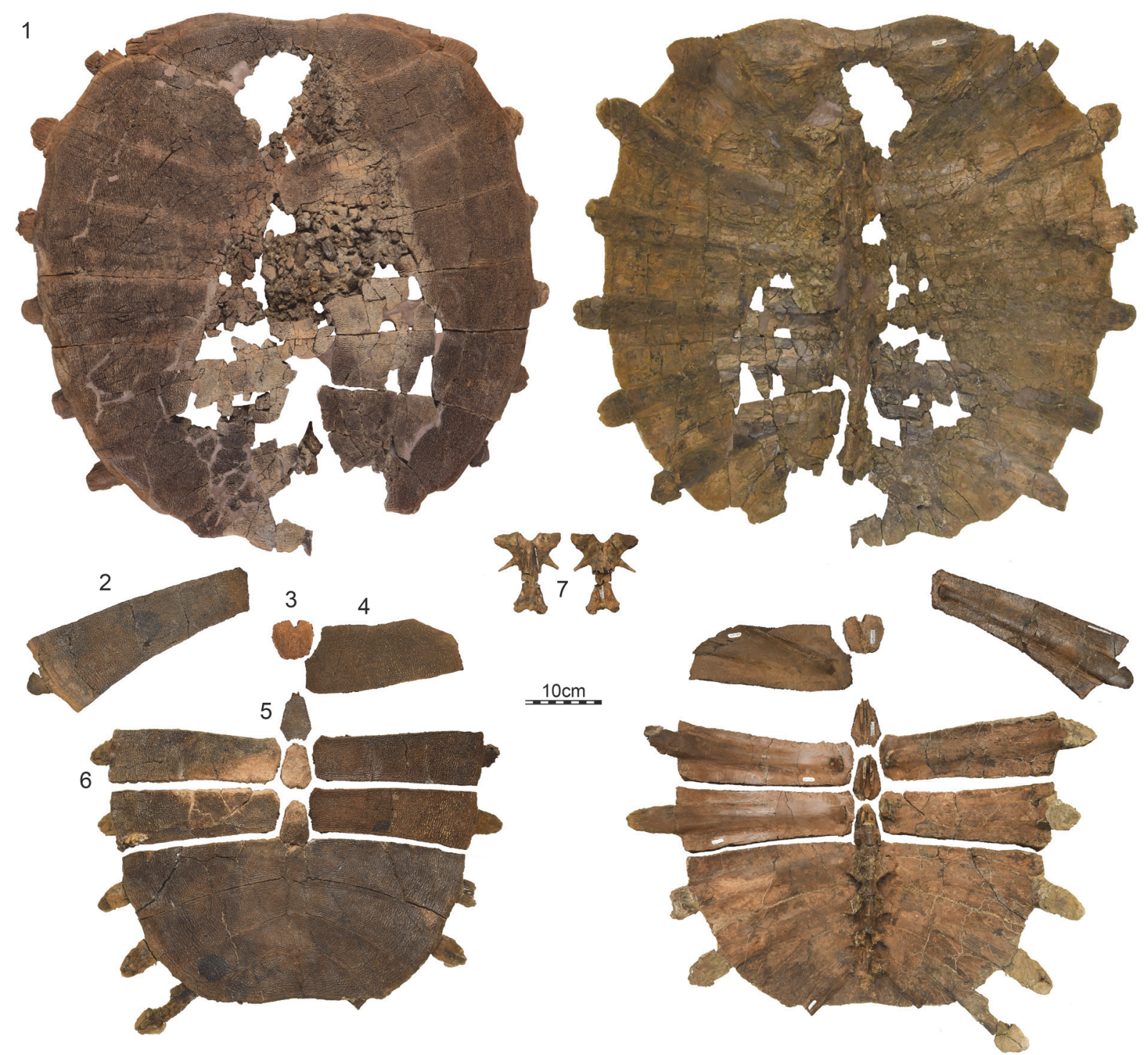

FIGURE 7. Axestemys infernalis sp. nov. from the Late Cretaceous (Maastrichtian) Big Turtle Cove locality of Slope County, North Dakota, USA. Photographs of (1) DMNH 131100, holotype, partial carapace in dorsal and ventral views; (2) DMNH 130958, costal VI in dorsal and ventral views; (3) DMNH 130949, preneural in dorsal and ventral views; (4) DMNH 130957, costal I in dorsal and ventral views; (5) DMNH 130948, neural in dorsal and ventral views; (6) DMNH 97045, posterior two thirds of carapace in dorsal and ventral views; (7) DMNH 130942, dorsal vertebra I in dorsal and ventral views. See Figure 8 for line drawings of these specimens.

sion that is sutured to the preneural and the medial portions of costal I, and that only covers the posteromedial portions of the underlying nuchal processes. There is no evidence of suprascapular fontanelles. At its greatest (e.g., Figure 3.1), the nuchal callosity is elongate, is broadly sutured to costal I, and fully covers the nuchal processes in dorsal view, with exception of their most lateral tips. Although there is a general correlation in that larger individuals have larger callosities, intermediately sized individuals from the Turtle Bonebed have disproportionally larger callosities (e.g., Figures 3.1,
4.2) relative to large individuals from other localities (e.g., Figures 7.1, 13, 14). These differences may be of taxonomic significance (see Discussion). Neural column: The complete neural column is preserved in only four individuals (Figures 2, 3, 4.1, 15 ), but additional information can be gleaned from the remaining specimens with partial neural series. The neural column universally includes a preneural. This element is about as long as a neural, but typically a little wider. It contacts the nuchal anteriorly along a convex suture, neural I posteriorly along a straight suture, and costal I laterally. The 

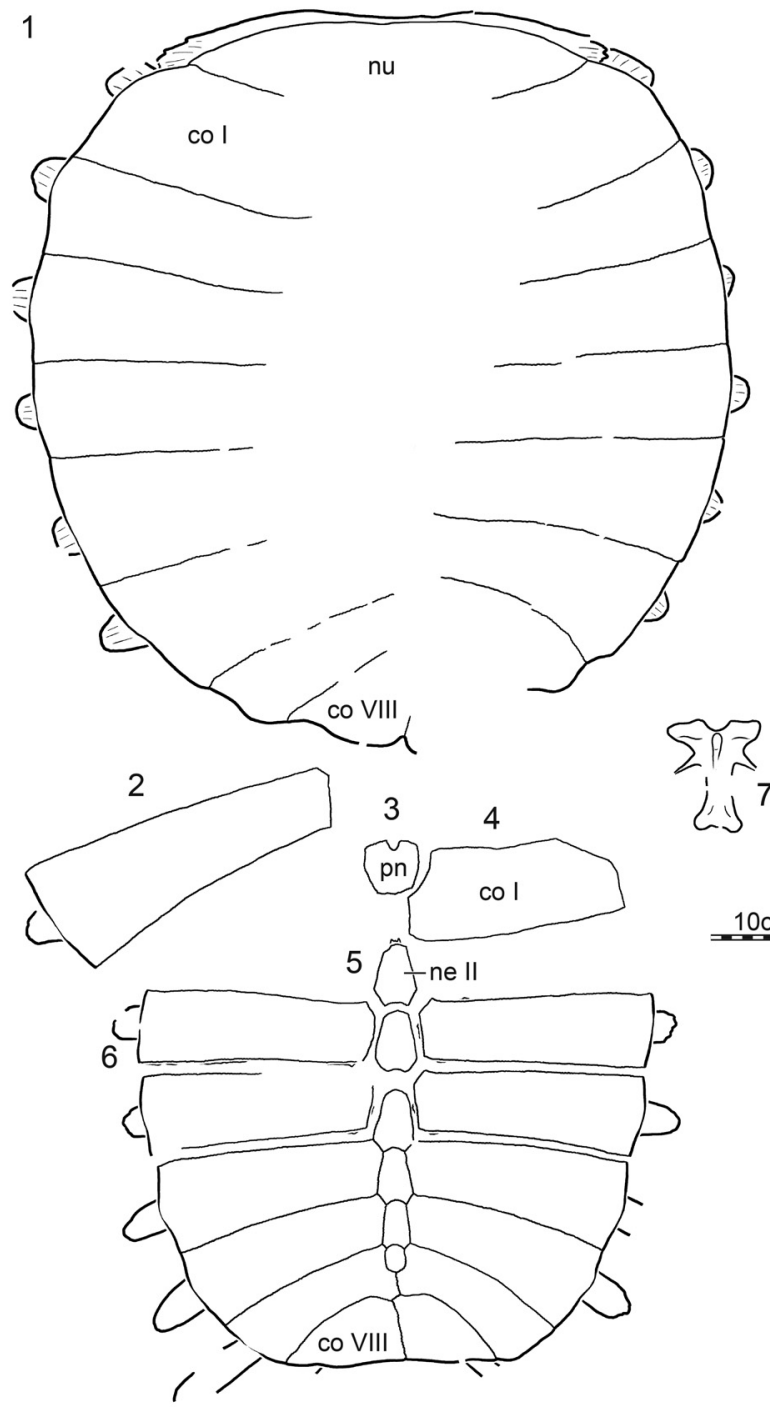
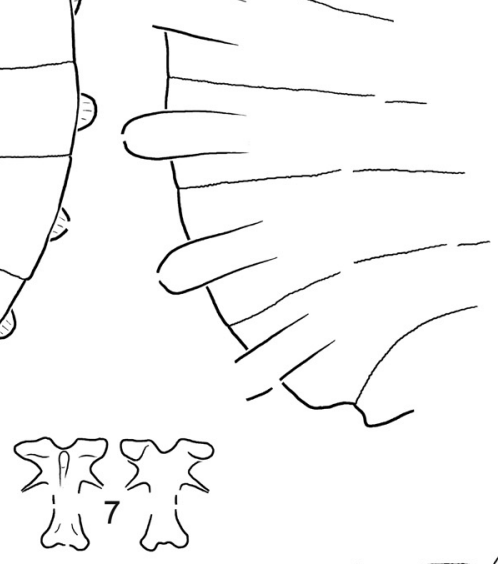

$10 \mathrm{~cm}$
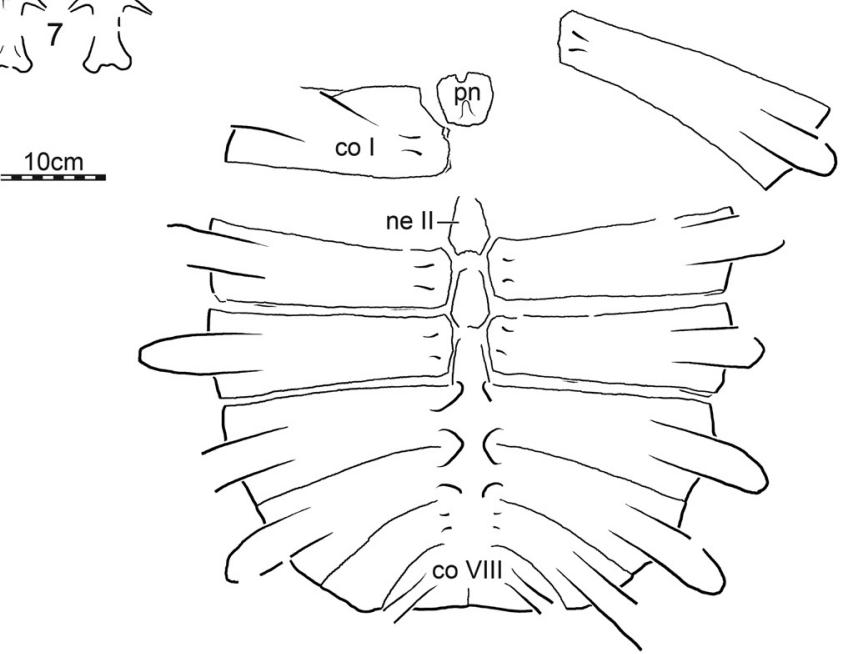

FIGURE 8. Axestemys infernalis sp. nov. from the Late Cretaceous (Maastrichtian) Big Turtle Cove locality of Slope County, North Dakota, USA. Line drawings of specimens depicted in Figure 7. Abbreviations: co = costal; ne = neural; $\mathrm{nu}=$ nuchal; $\mathrm{pn}=$ preneural.

number of neurals varies. Two specimens have six neurals (Figures 4.1,15), four have seven neurals (Figures $3,7.6,12.7,17.1$ ), and one has eight neurals (Figure 2). The neural column is reversed in three specimens at neural VI (Figures 2, 3, 17.1), but a reversal is absent in the three remaining specimens where this character can be observed (Figures 4.1, 8.5, 16.1). The number of neurals and the presence of a reversal are known to be highly variable in many extant trionychids (Meylan, 1987), and these differences therefore may not have taxonomic significance.

Costals: The carapace includes eight pairs of costals. Costals I and II are slightly oriented anteriorly, costals III and IV laterally, and costals V to VIII increasingly to the posterior. All costals have similar anteroposterior dimensions along the midline, with exception of costal I, which is more elongate. Most costals have similar dimensions proximally and distally, with exception of costal I, which is constricted distally, and costals II, V, and VI, which tend to be expanded distally. Costals I-VI have similar width, but costals VII and VIII are significantly shorter. Much variation is apparent in the size and proportions of costal VIII, ranging from about as wide as long (e.g., Figures 2, 4.1, 7.1, 17.1) to much wider than long (e.g., Figures 3, 7.6, 15).

The carapace has nine dorsal vertebrae and ribs. As in all extant trionychids, dorsal vertebrae and rib $\mathrm{X}$ were probably present, but are not pre- 

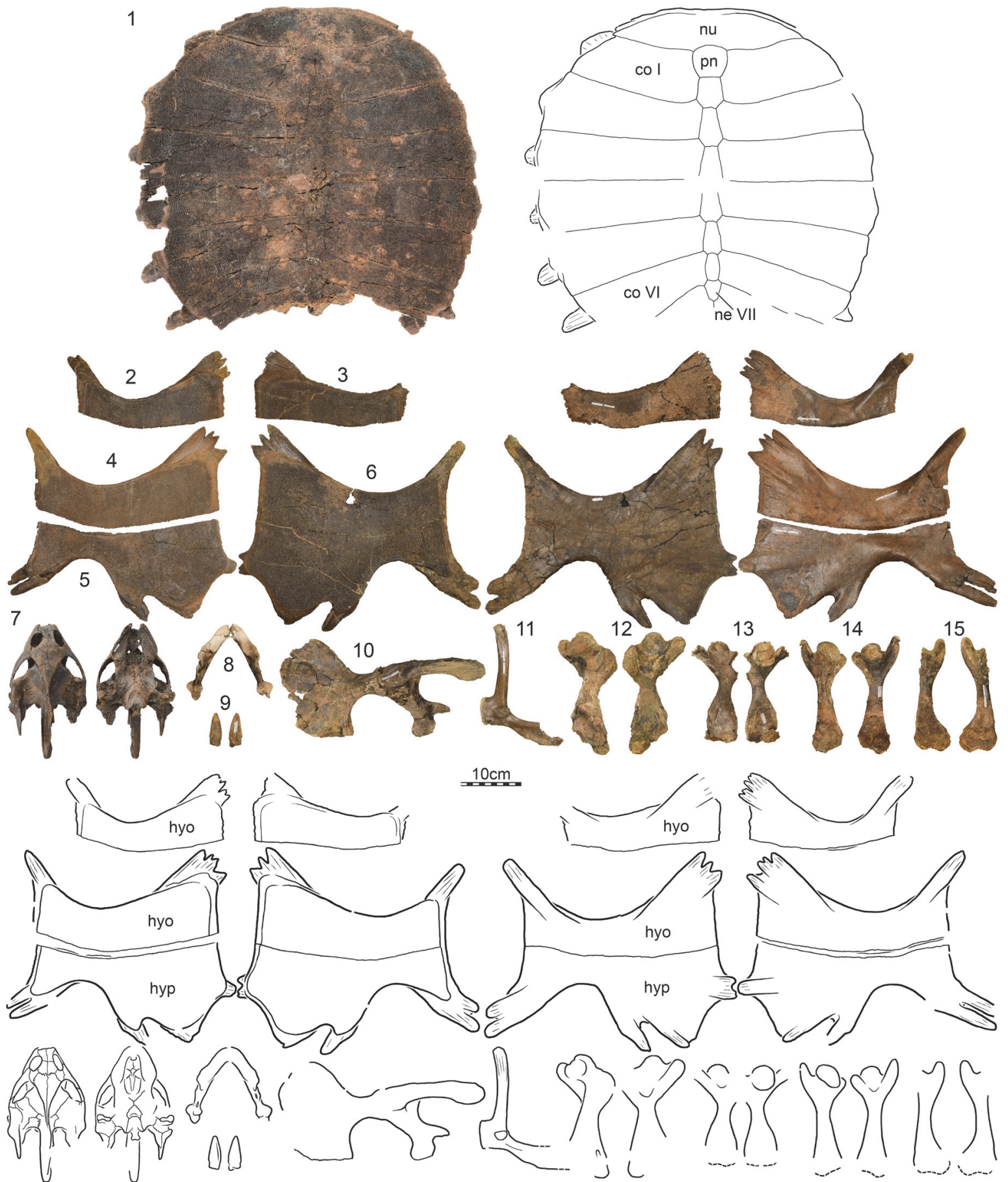

FIGURE 9. Axestemys infernalis sp. nov. from the Late Cretaceous (Maastrichtian) Big Turtle Cove locality of Slope County, North Dakota, USA. Photographs and line drawings of (1) DMNH 97093, a nearly complete carapace in dorsal view; (2) DMNH 130959, right hyoplastron in ventral and dorsal views; (3) DMNH 130963, left hyoplastron in ventral and dorsal views; (4) DMNH 130964, right hyoplastron in ventral and dorsal views; (5) DMNH 130956, right hypoplastron in ventral and dorsal views; (6) DMNH 130954, left hyo/hypoplastron in ventral and dorsal views; (7) DMNH 130951, cranium in dorsal and ventral views; (8) DMNH 130952, mandible in dorsal view; (9) DMNH 130947, ungual phalanx in dorsal and palmar views; (10) DMNH 130955, right pelvis in dorsal view; (11) DMNH 130943, right partial scapulocoracoid in medial view; (12) DMNH 130953, left humerus in dorsal and ventral views; (13) DMNH 130945, right humerus in ventral and dorsal views; (14) DMNH 130950, right femur in dorsal and ventral views; (15) DMNH 130946, left femur in dorsal and ventral views. Abbreviations: co $=$ costal; hyo $=$ hyoplastron; hyp $=$ hypoplastron; ne = neural; nu = nuchal; $p n=$ preneural. 

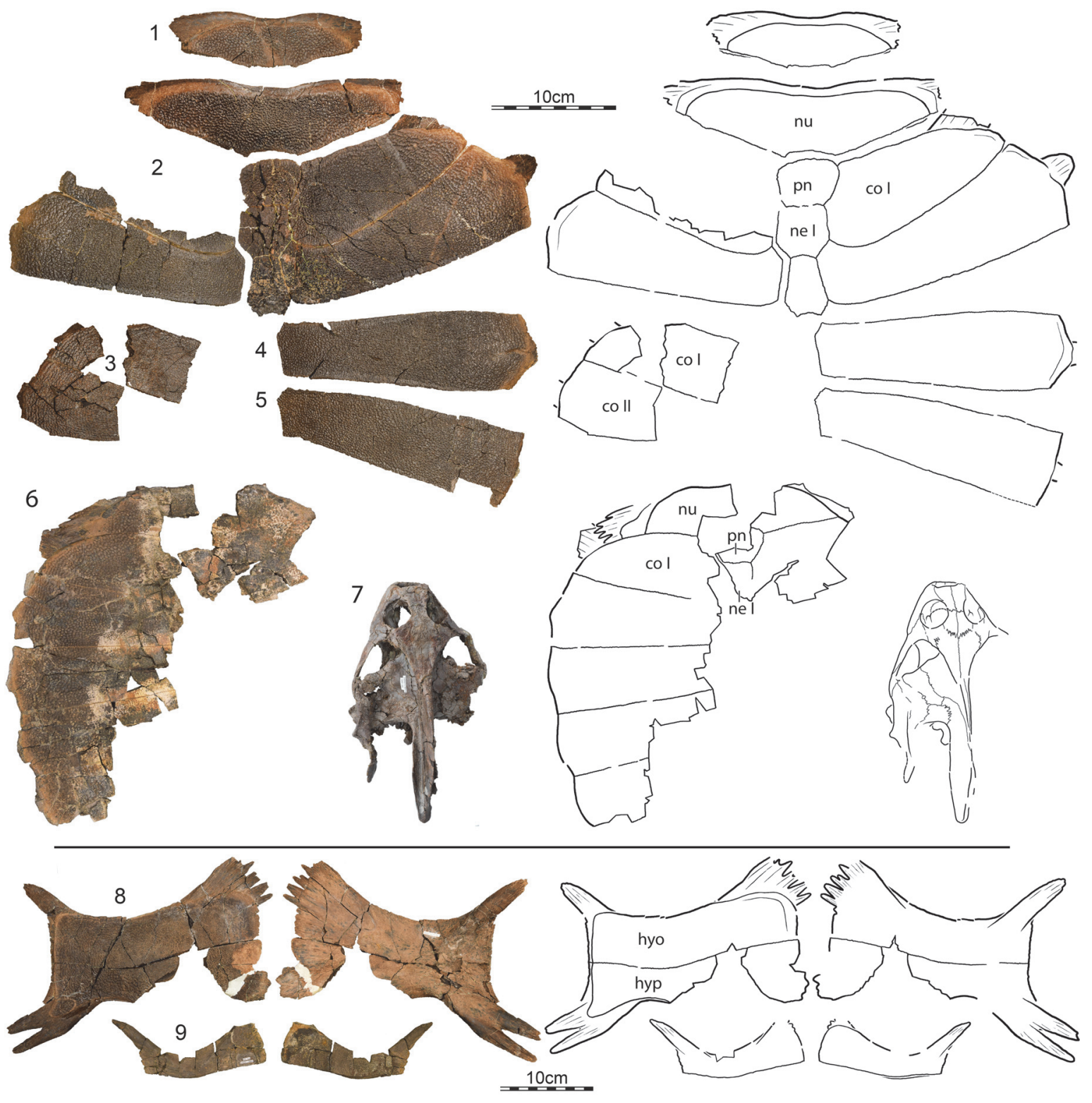

FIGURE 10. Axestemys infernalis sp. nov. from the Late Cretaceous (Maastrichtian) Turtle Ridge locality of Slope County, North Dakota, USA. Photographs and line drawings of (1) DMNH 98825, a nuchal, in dorsal view; (2) DMNH 97037, anterior portions of carapace, in dorsal view; (3) DMNH 98809, parts of left costal I and II, in dorsal view; (4) DMNH 98824, right costal IV in dorsal view; (5) DMNH 98831, right costal V, in dorsal view; (6) DMNH 97027, anterior portions of carapace, in dorsal view; (7) DMNH 98814, a partial cranium, in dorsal view; (8) DMNH 97038, right hyo/hypoplastron in ventral and dorsal views; (9) DMNH 98863, left hyoplastron in dorsal and ventral views. Abbreviations: $\mathrm{co}=$ costal; hyo = hyoplastron; hyp $=$ hypoplastron; $\mathrm{ne}=$ neural; $\mathrm{nu}=$ nuchal; $\mathrm{pn}=$ preneural.

served as they likely disarticulated post mortem. The anterior margin of dorsal vertebra I reaches the medial third of the nuchal (Figure 14). As in all trionychids, the prezygapophyses are well developed, but the anterior articular surface of the centrum is absent (Figures 7.7, 14). Dorsal vertebrae II-VIII are platycoelous, articulate with the shell dorsally, and have broad sutural contacts with the ribs laterally. The vertebrae and ribs form a low costovertebral tunnel similar in dimension to that of most other trionychids (e.g., Figure 14). Dorsal ribs II-IX (= costal ribs I-VIII) are associated with costals IVIII. All costal ribs have free distal ends, but these are shorter in larger specimens, highlighting a possible ontogenetic trend. Costal rib $I$ is expanded anteriorly, oriented anterolaterally, and distally 


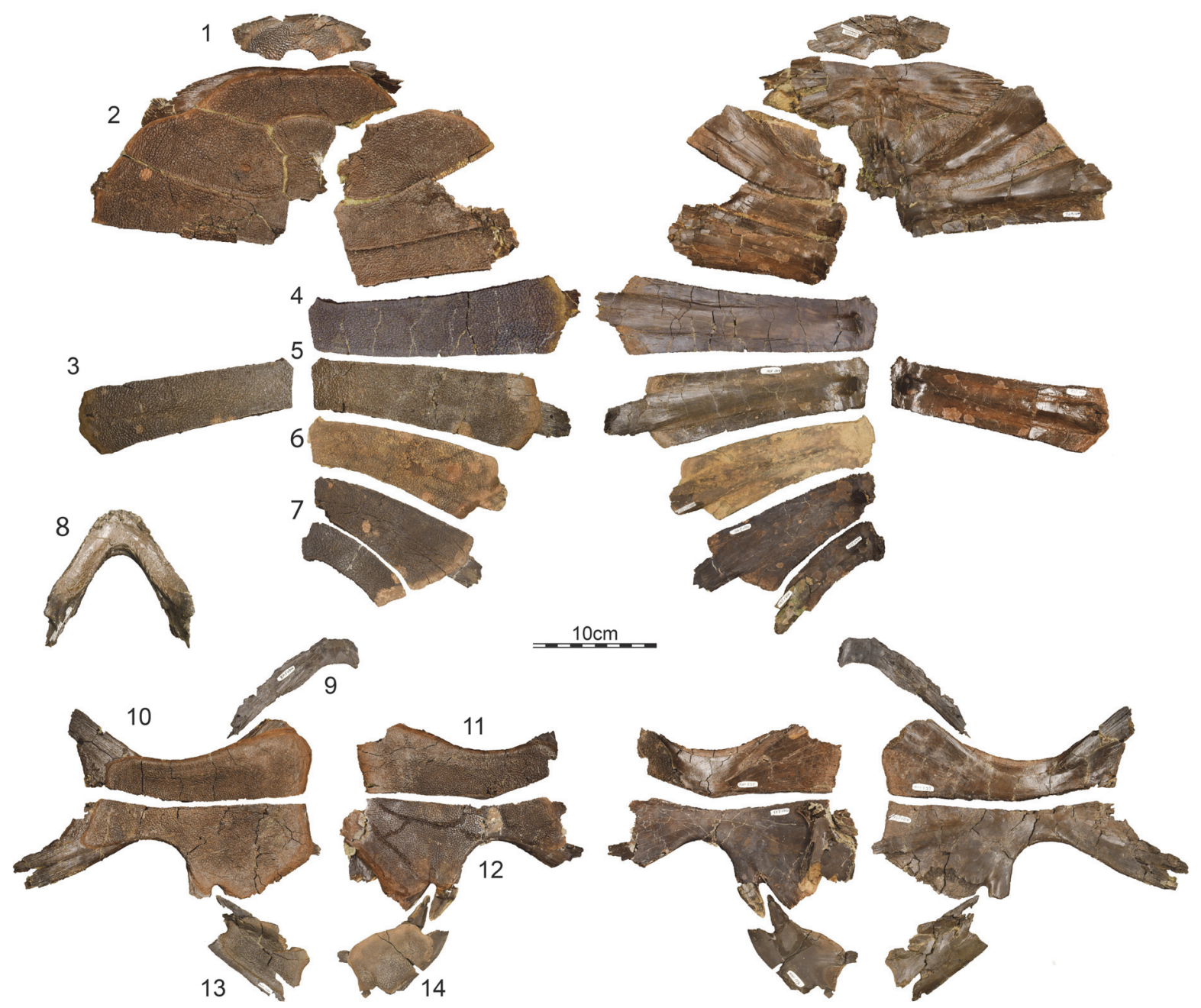

FIGURE 11. Axestemys infernalis sp. nov. from the Late Cretaceous (Maastrichtian) Turtle Graveyard locality of Slope County, North Dakota, USA. Photographs of (1) DMNH 97021, nuchal in dorsal and ventral views; (2) DMNH 130931, anterior portions of carapace in dorsal and ventral views; (3) DMNH 125911, left costal V in dorsal and ventral views; (4) DMNH 130934, right costal IV in dorsal and ventral views; (5) DMNH 130932, right costal $\mathrm{V}$ in dorsal and ventral views; (6) DMNH 96955, right costal VI in dorsal and ventral views; (7) DMNH 130935, right costal VI and VII in dorsal and ventral views; (8) DMNH 96928, partial mandible in dorsal view; (9) DMNH 125912, partial entoplastron in ventral and dorsal views; (10) DMNH 130927, right hyo/hypoplastron in ventral and dorsal views; (11) DMNH 130929, left hyoplastron in ventral and dorsal views; (12) DMNH 125919, left hypoplastron in ventral and dorsal views; (13) DMNH 125913, right xiphiplastron in ventral and dorsal views; (15) DMNH 125914, left xiphiplastron in ventral and dorsal views. See Figure 12 for line drawings of these specimens.

underlies the distal ends of the nuchal processes. Costal ribs II-VI have similar proportions to one another, have short free ends, do not expand distally, and are mostly oriented laterally. Costal rib VII is slightly narrower than the more anterior costal ribs, is more strongly oriented posteriorly, and has a proportionally longer free end. Costal rib VIII is not fully preserved in any specimen, but remnants indicate that it was significantly narrower than all more anterior costal ribs and likely had an elongate free distal end (e.g., Figures 7.6, 15.2).
Plastron. We figure the plastral remains of at least 15 individuals that vary greatly in size (Figures 5, 9, $10,11,16,17)$. The plastron consists of an entoplastron and pairs of epiplastra, hyoplastra, hypoplastra, and xiphiplastra. There is no evidence of supernumerary plastral bones. Only the hyoplastra, hypoplastra, and xiphiplastra are associated with callosities. The central portions of these callosities are covered by surficial texturing, but broad margins remain bare. The sculpturing pattern of the plastral callosities is finer grained than that of 


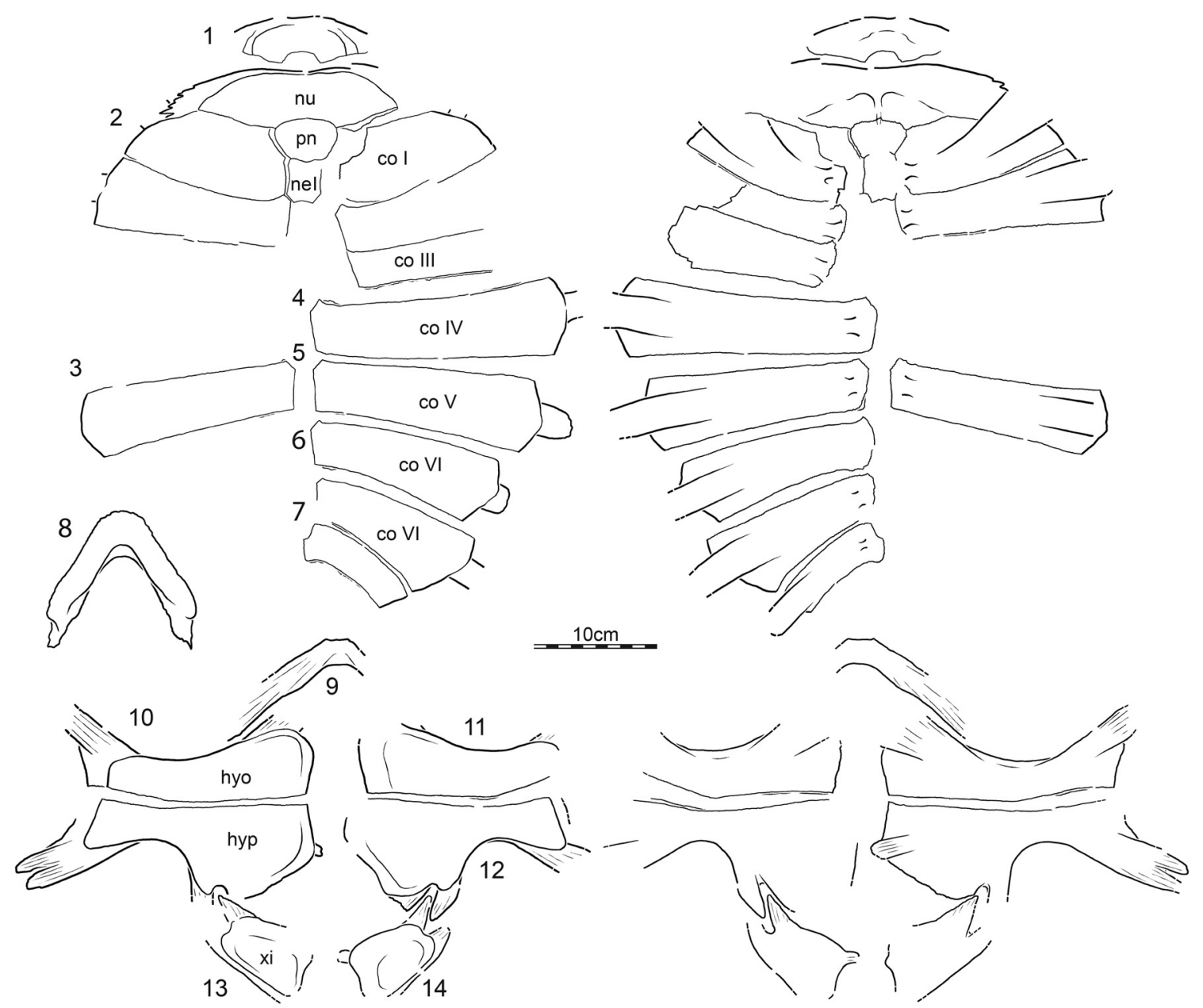

FIGURE 12. Axestemys infernalis sp. nov. from the Late Cretaceous (Maastrichtian) Turtle Graveyard locality of Slope County, North Dakota, USA. Line drawings of specimens depicted in Figure 11. Abbreviations: co = costal; hyo = hyoplastron; hyp = hypoplastron; ne = neural; nu = nuchal; pn = preneural; $x i=$ xiphiplastron.

the carapace and ranges from irregularly netted to irregularly punctate.

Epiplastron: The epiplastra are only available from medium-sized individuals from the Turtle Bonebed (Figure 5) and Sandy sites (Figure 16). These elements universally lack callosities. The epiplastra consist of a short anterior process and an elongate lateral process. The anterior process ranges from rounded to flattened and from about 50 to 80 percent of the length of the lateral process. The lateral process tapers distally and exhibits a groove for articulation with the entoplastron. The shape of the entoplastron (see below) suggests that the epiplastra were widely spaced from one another.

Entoplastron: Entoplastra are only available from medium-sized individuals from the Turtle Bonebed (Figure 5) and Turtle Graveyard sites (Figure 11.9). Similar to the epiplastra, these elements lack any evidence of callosities, and it is unlikely that they would have been present in larger individuals. The entoplastron consists of two posterolateral processes and a central, transverse plateau. The lateral corners that define this plateau denote the former position of the epiplastra in disarticulated specimens (Figure 5.5). The epiplastra can therefore be deduced to have been widely spaced from one another. The angle between the lateral processes is about 85 degrees. A minor notch is apparent in dorsal view along the medial sides of the lateral processes for articulation with the hyoplastron.

Hyo/Hypoplastron: Hyo/hypoplastral material of all size classes is available from several sites (Figures $5,9,10,11,16,17)$. The hyoplastron has a single lateral process and variably forms a fine to coarse comb of medial processes that fill about half of the medial margin of the element. The hypoplastral forms two distinct lateral processes, but the medial 


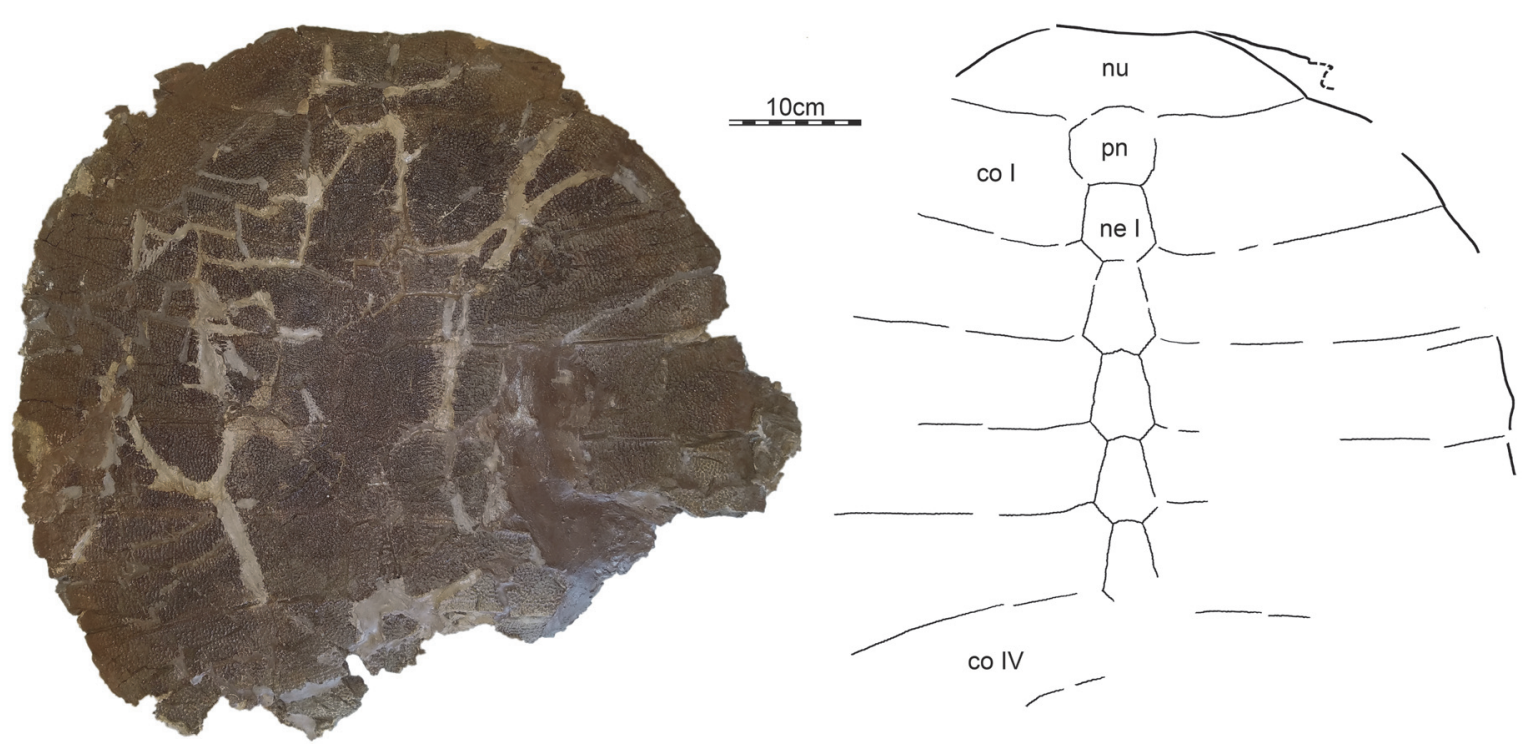

FIGURE 13. Axestemys infernalis sp. nov. from the Late Cretaceous (Maastrichtian) of Dawson County, Montana, USA. Photograph and line drawings of AMNH 14149, a partial carapace, in dorsal view. Abbreviations: co = costal; ne = neural; nu = nuchal; pn = preneural. Photograph courtesy of Division of Paleontology, AMNH, New York.

comb is split into two groups by a distinct gap. The anterior portion of the comb consists of a welldeveloped process that may be split distally for articulation with its counterpart (e.g., Figure 9.2-6). The posterior portion of this comb consists of at least two well-developed processes that frame a deep triangular notch for articulation with the xiphiplastron, but additional, minor processes may be present further anteriorly.

The hyoplastron and hypoplastron form separate callosities that are broadly sutured to one another, but never fuse, even in the largest available specimens (Figure 9.2-6). The size of hyoplastral callosity correlates with the size of the specimen. In the smallest available specimen the callosity barely covers the axillary portions of the hyoplastral processes, but nevertheless has a broad contact with the hypoplastral callosity (Figure 5.8). The lateral and medial processes are therefore free. The central portion of the callosity is sculpted. In the largest available hyoplastra, the callosity expands beyond the anterior margin of the axillary portions of the hyoplastral processes, but the anterior margin does not form an anterior convexity (i.e., plastomenid "shoulder") relative to the medial hyoplastral processes (Figure 9.2-6). The callosity extends medially and laterally, but much of the distal ends of the overlying processes are still visible in ventral view. In the smallest available specimen, the hypoplastral callosity is similarly restricted to the inguinal portions of the element (Figure 5.8), but this callosity nearly expands to the medial and lateral margins of the overlying in the largest available specimens (Figure 9.2-6). Some variation is apparent in the posterior development of the hypoplastral callosity. In general, larger specimens have callosities that cover the two posterior hypoplastral processes that frame the triangular notch that serves for articulation with the xiphiplastron, but this callosity is relatively better developed in intermediately sized individuals from the Turtle Bonebed locality (Figure 5.14) and Lance Formation (Figure 17.2) than in much larger individuals from the Big Turtle Cove locality (Figure 9.2-6). This may have taxonomic significance. The hyo/hypoplastral callosities do not have a midline contact with one another, but may have bluntly contacted the xiphiplastral callosities in individuals with particularly well-developed callosities.

Xiphiplastron: Xiphiplastra of small- to mediumsize individuals are available from the Turtle Bonebed (Figure 5), Turtle Graveyard (Figure 11), the Sandy Site (Figure 16), and the Lance Formation (Figure 17) and exhibit considerable variation. The xiphiplastron forms two anterior processes, of which the medial one inserts into the triangular notch formed by the two dominated posteriorly processes of the hypoplastron. The xiphiplastron furthermore forms a broad posterior process and a narrow medial process that is sometimes split distally for articulation with its counterpart. In the smallest available specimen (Figure 5.15), the xiphiplastral callosity only protrudes beyond the overlying processes anteriorly and medially. In the 


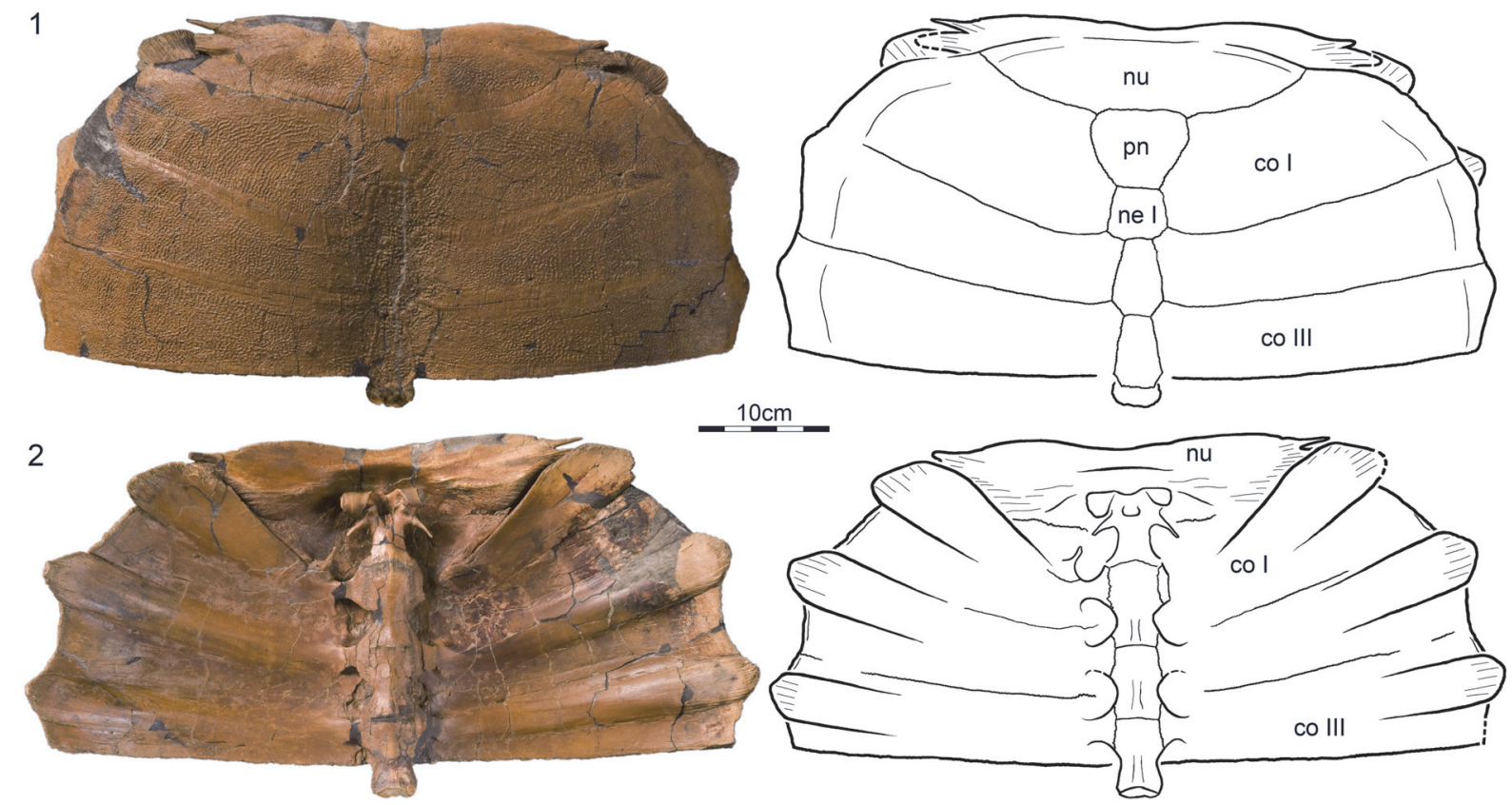

FIGURE 14. Axestemys infernalis sp. nov. from the Late Cretaceous (Maastrichtian) of Garfield County, Montana, USA. Photograph and line drawings of LACM 15432 in (1) dorsal and (2) ventral views. Abbreviations: $c 0=c o s t a l ; n e$ = neural; nu = nuchal; pn = preneural. Photograph courtesy of the Dinosaur Institute, LACM, Los Angeles.

largest available specimen, the callosity (Figure 5.23 ) is expanded anteriorly and medially to fully cover the overlying processes with exception of their tips, but the callosity only expands laterally beyond the margin of the process a little. The callosity is nearly fully covered by sculpturing.

Cranium. Three crania associated with postcranial remains of Axestemys are preserved from three different sites: DMNH 130951 from the Big Turtle Cove, DMNH 98814 from Turtle Ridge, and NSM PV24650 from the Sandy Site (Figure 18). Although DMNH 98814 was recently described by Vitek (2012), it is the most poorly preserved cranium and the only one available to her at the time. We therefore provide an updated description, mostly by reference to DMNH 130951, which is the best-preserved cranium.

DMNH 130951 has an approximate midline length from the tip of the snout to the base of the occipital condyle of $15.0 \mathrm{~cm}$. Using the same metrics, DMNH 98814 has a length of $14.5 \mathrm{~cm}$ and NSM PV24650 a length of $16.0 \mathrm{~cm}$. The entire preserved length of DMNH 130951 is approximately $21.5 \mathrm{~cm}$. DMNH 130951 only shows minor dorsoventral crushing and damage to the right squamosal. DMNH 98814 is more strongly crushed dorsoventrally and much of the posterior right half of the cranium is missing. The anterior half of NSM PV24650 is well preserved, but the posterior half of the cranium is damaged and has undergone significant repairs. Although all three crania are similar in size, DMNH 98814 appears to be the most juvenile by having a more elongate shape and narrow triturating surfaces compared to the other crania. NSM PV24650, by contrast, appears to be the most adult by having a broader skull shape and expanded triturating surfaces. Joyce et al. (2016) noted similar ontogenetic changes for the extant Amyda cartilaginea and the fossil Gilmoremys lancensis.

Prefrontal: The prefrontal roofs the anterior half of the interorbital space, forms the dorsal margin of the external nares, and the anterodorsal rim of the orbit. The prefrontal contacts the maxilla anteroventrally along an anteriorly sloping suture, the frontal posteriorly along a transverse suture, and the vomer within the orbit. The prefrontals jointly form a minor anterior protrusion. The apertura narium externa therefore possesses minor dorsolateral emarginations.

Frontal: The frontal roofs the posterior half of the interorbital space. It contacts the prefrontal anteriorly along a transverse suture, the postorbital posterolaterally, and the parietal posteriorly along a deeply interfingering suture that varies in its shape among the three available specimens. Together with the prefrontal, the frontal forms a shallow sulcus olfactorius. 

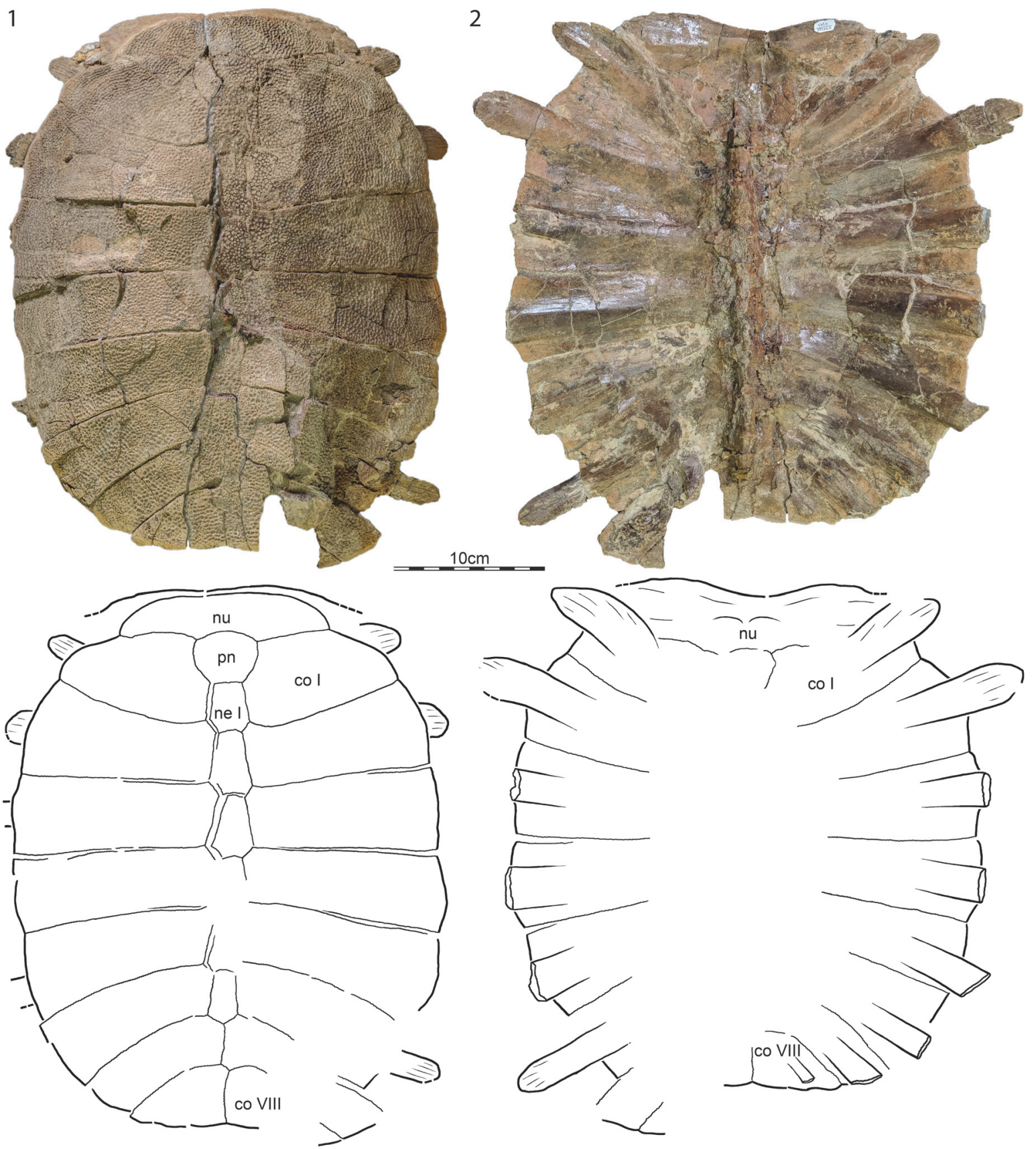

FIGURE 15. Axestemys infernalis sp. nov. from the Late Cretaceous (Maastrichtian) of McCone County, Montana, USA. Photograph and line drawings of RAM 9393 in (1) dorsal and (2) ventral views. Abbreviations: co = costal; ne = neural; nu = nuchal; $p n=$ preneural. Photograph courtesy of the RAM, Claremont.

Parietal: The parietals form the posterior half of the skull roof. It contacts the frontal anteriorly along an irregular, deeply interdigitated suture and the postorbitals anterolaterally. In contrast to Vitek (2012), we find no evidence of the parietal contributing to or even approaching the margin of the orbit in any specimen, including DMNH 98814. Within the upper temporal fossa, the descending process of the parietal contacts the prootic posterolaterally and the supraoccipital posteriorly. The anterior margin of this process forms a distinct step in all specimens that delineates the medial margin of the trochlear process. More anteriorly the process contacts the palatine and pterygoid and roofs the anterodorsal margin of the trigeminal foramen. 


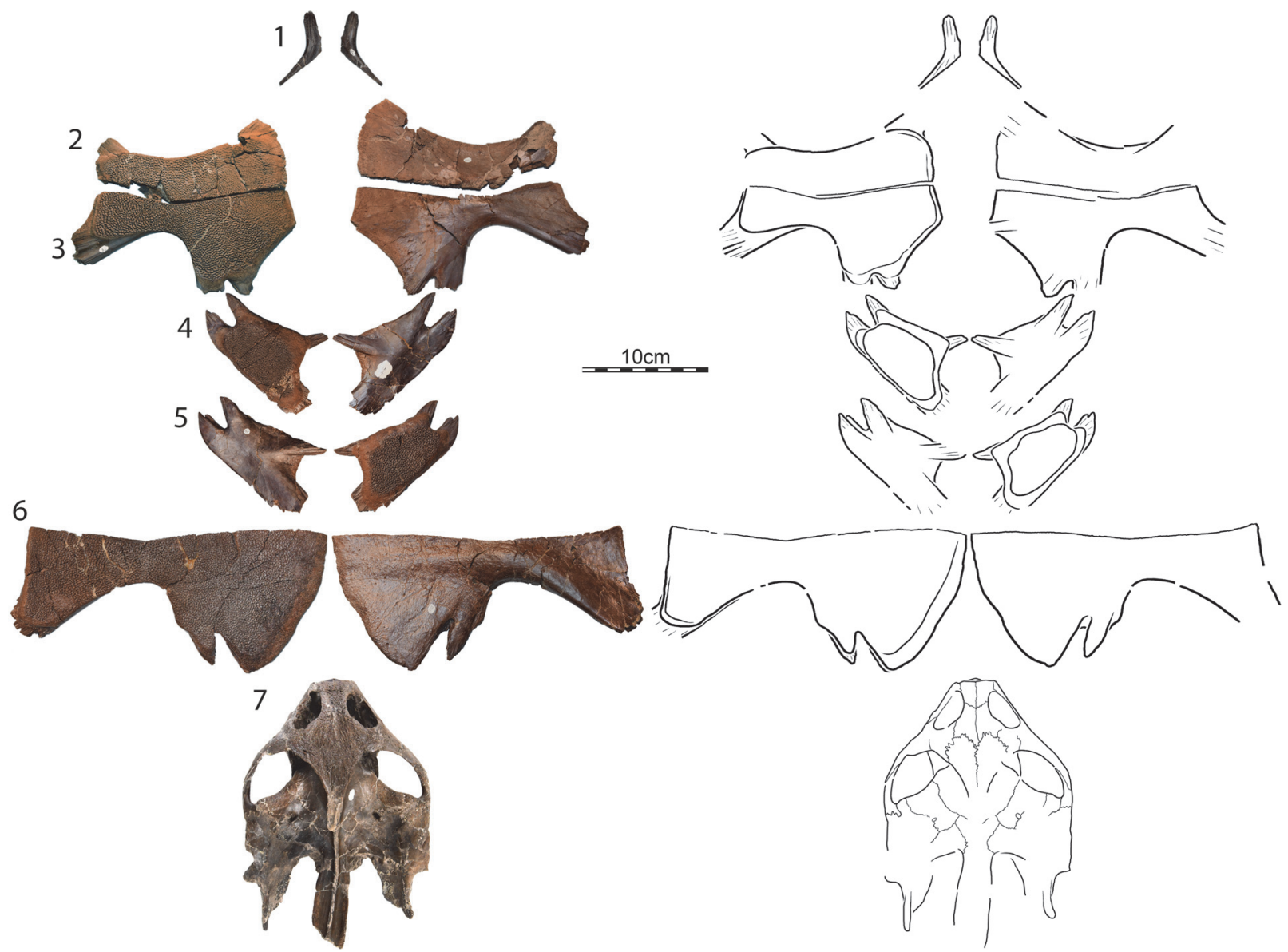

FIGURE 16. Axestemys infernalis sp. nov. from the Late Cretaceous (Maastrichtian) of Harding County, South Dakota, USA. Photographs and line drawings of (1) NSM PV24644, a right epiplastron, in ventral and dorsal views; (2) NSM PV24645, a right hyoplastron, in ventral and dorsal views; (3) NSM PV24646, a right hypoplastron, in ventral and dorsal views; (4) NSM PV24647, a right xiphiplastron, in ventral and dorsal views; (5) NSM PV24648, a left xiphiplastron, in dorsal and ventral views; (6) NSM PV24649, a right hypoplastron, in ventral and dorsal views; (7) NSM PV24650, a cranium, in dorsal and ventral views.

Postorbital: The postorbital is similar in size to the frontal and forms much of the postorbital bar. It forms the posterodorsal margin of the orbit and the anteromedial margin of the upper temporal emargination, and contacts the frontal anteromedially, the parietal posteromedially, and the jugal ventrolaterally. The postorbital bar is approximately one half of the diameter of the orbit.

Jugal: The jugal is a massive bone that forms the posteroventral margin of the orbit and the anterior two-thirds of the temporal arch. This bone contacts the postorbital dorsally and the maxilla anteriorly, and broadly overlaps the quadratojugal posteriorly. Lateral contact with the parietal and posterior contact with the squamosal are blocked in all available specimens by the postorbital and quadratojugal, respectively. Within the orbit, the jugal has a short anterior contact with the maxilla and a broad, medial contact with the palatine.

Quadratojugal: The quadratojugal is an elongate bone that frames the anterior margin of the cavum tympani and forms the posterior third of the temporal arch. It is anteriorly overlapped by the jugal. Laterally it forms an extension that medially contacts the quadrate and caps the trochlear process, and posteriorly it contacts the quadrate and squamosal. Squamosal: With the exception of the left squamosal of DMNH 130951, all available squamosals are damaged. The squamosal is a cone-shaped element that forms the voluminous antrum postoticum. In lateral view the squamosal forms the posterior and dorsal margins of the cavum tympani, contacts the quadrate ventrally behind the cavum tympani, and the quadratojugal anteriorly above the cavum tympani. In dorsal and ventral 


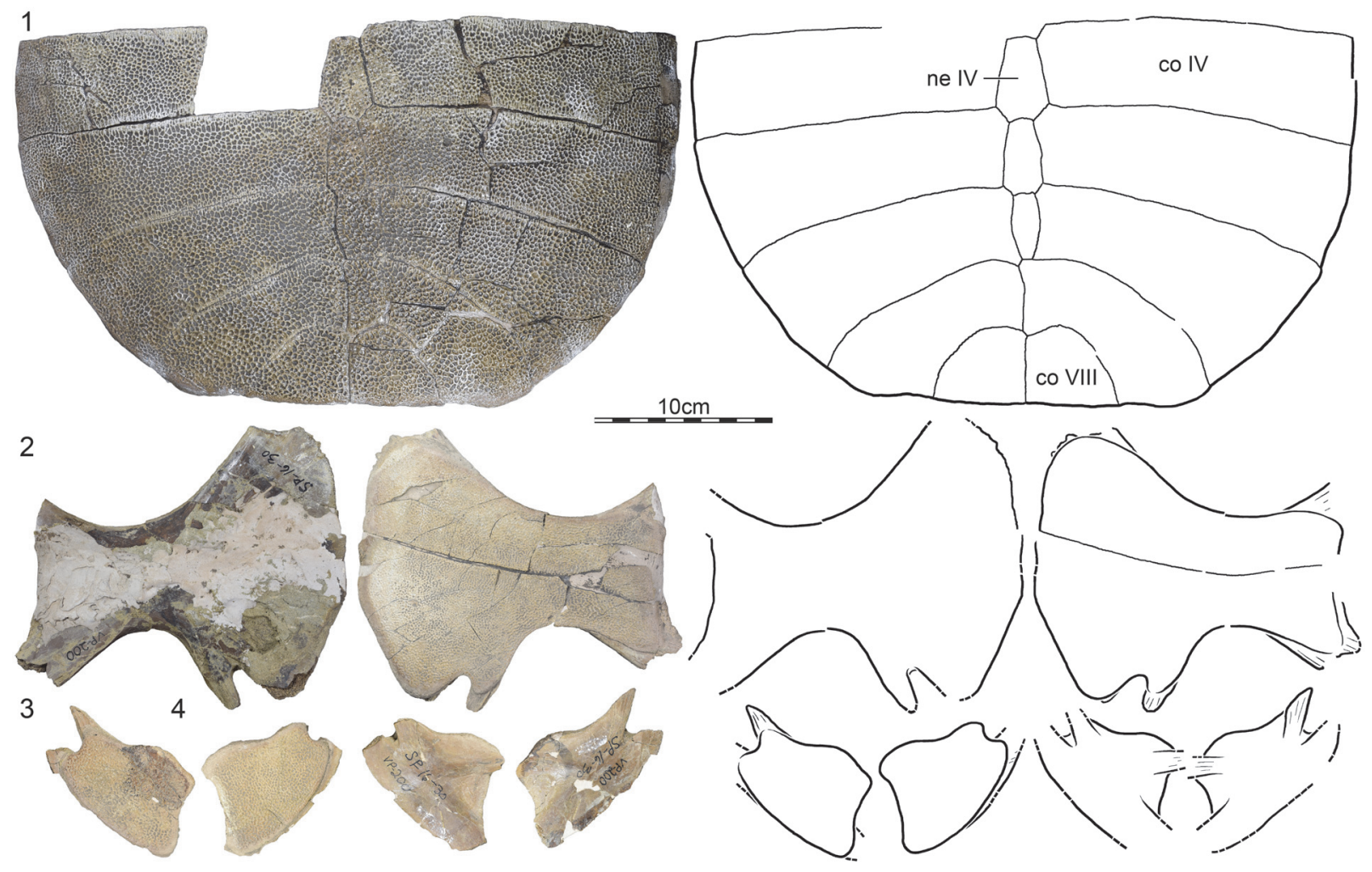

FIGURE 17. Axestemys infernalis sp. nov. from the Late Cretaceous (Maastrichtian) of Niobrara County, Wyoming, USA. Photographs and line drawings of (1) the posterior portion of the carapace in dorsal view and of the (2) the left hyo/hypoplastron, (3) the right xiphiplastron, and (4) the left xiphiplastron in ventral and dorsal views of FHSM VP200. Two neurals and two partial costals mounted with this specimen were digitally removed, as they do not appear to belong to the same individual. Abbreviations: $c o=$ costal; ne $=$ neural.

views, the squamosal forms an elongate posterior process that extends well beyond the occipital condyle. An elongate lateral depression for the depressor mandibulae is apparent posterior to the cavum tympani. Within the upper temporal fossa, the squamosal broadly contacts the quadrate anteriorly and medially and the paroccipital process of the opisthotic posteromedially.

Premaxilla: The fused premaxillae form a small element that forms the anterior portion of the labial margin and the anterior margin of the short foramen intermaxillaris. Medial contact of the maxillae dorsal to the premaxillae blocks access of the premaxillae to the external nares.

Maxilla: The maxilla is a large bone that forms the majority of the expanded triturating surfaces, floors the anterolateral portions of the orbit, and forms the ventral margin of the external nares. In lateral view, the maxilla is a broad element that forms the ventral margin of the orbit, broadly contacts the jugal posteriorly, the premaxilla anteriorly, the prefrontal anterodorsally, and its counterpart anteromedially along the ventral margin of the external nares.
Within the orbit, the maxilla contacts the descending process of the prefrontal anteromedially, the jugal posterolaterally, and the palatine posteromedially, and forms the lateral margin of the expanded foramen orbito-nasale. The canalis infraorbitalis runs within the orbit on the dorsal side of the maxilla parallel to the narial canal. Its anterior and posterior foramina are located within the maxilla and palatine, respectively. In ventral view, the maxilla forms the expanded triturating surfaces. These surfaces are mostly flat, with exception of a minor ridge that frames its medial margins. The maxilla contacts the premaxilla anteromedially, forms the lateral margins of the short foramen intermaxillare, contacts its counterpart and the vomer medially to form a short bridge between the foramen intermaxillare and internal nares, and contacts the palatines posteromedially and the pterygoid posteriorly. The small foramen palatinum posterius is formed jointly with the palatine.

Vomer: The vomer is an elongate bone that roofs the median portions of the primary palatine. The vomer forms a short anteroventral process that 

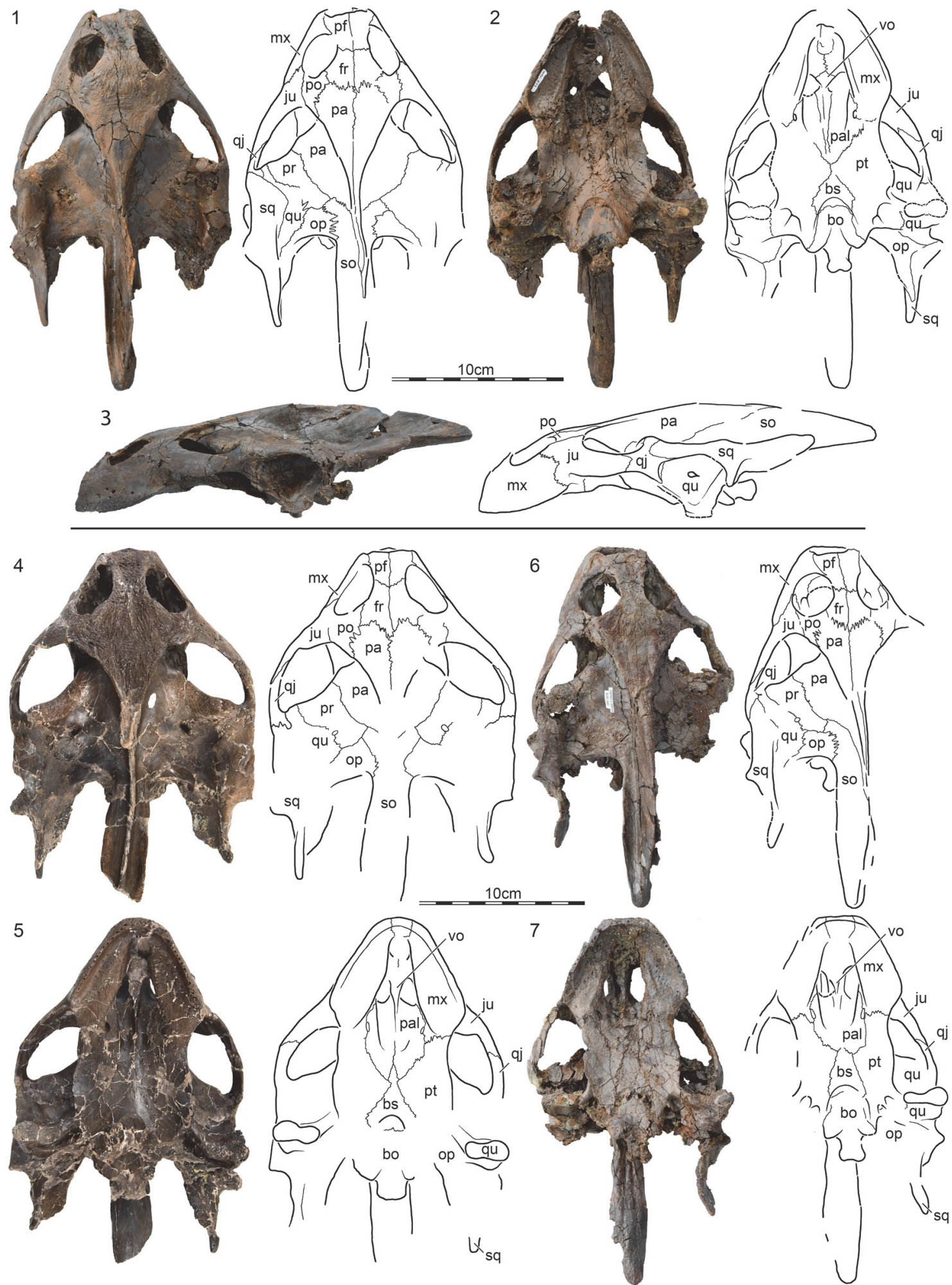

FIGURE 18. Enlarged photographs and line drawings of Axestemys infernalis sp. nov. crania from the Late Cretaceous (Maastrichtian) Hell Creek Formation. DMNH 130951 in (1) dorsal, (2) ventral, and (3) lateral views; NSM PV24650 in (4) dorsal and (5) ventral views; DMNH 98814 in (6) dorsal and (7) ventral views. Abbreviations: bo = basioccipital; bs = basisphenoid; $\mathrm{fr}=$ frontal; ju = jugal; $\mathrm{mx}=$ maxilla; $\mathrm{op}=$ opisthotic; pa = parietal; pal = palatine; $\mathrm{pf}=$ prefrontal; po = postorbital; $\mathrm{pr}=$ prootic; $\mathrm{pt}=$ pterygoid; $\mathrm{qj}=$ quadratojugal; $\mathrm{qu}=$ quadrate; $\mathrm{so}=$ supraoccipital; $\mathrm{sq}=$ squamosal; vo = vomer. 

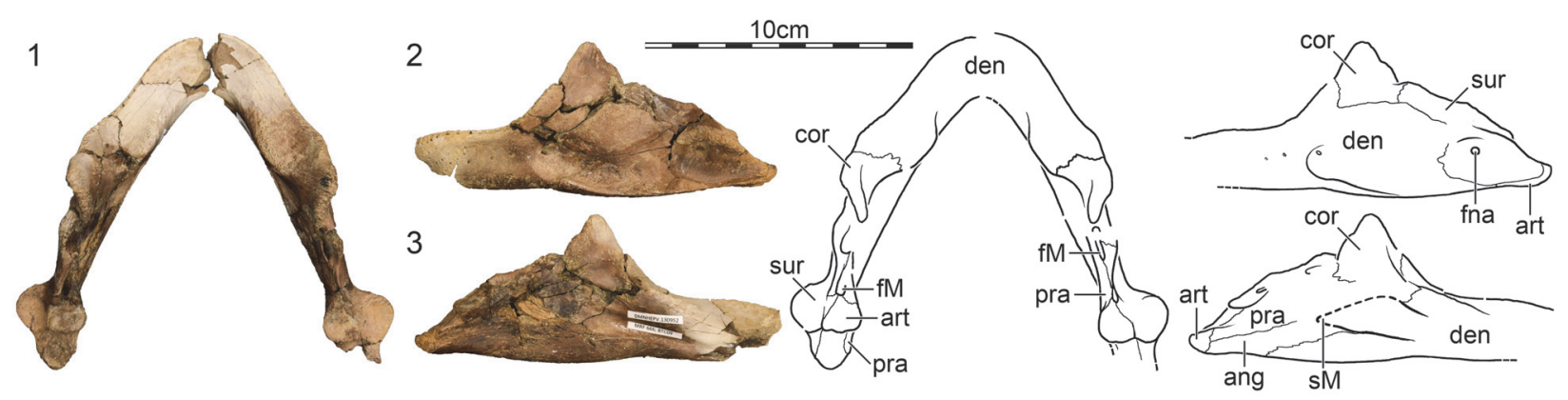

FIGURE 19. Enlarged photographs and line drawings of an Axestemys infernalis sp. nov. mandible from the Late Cretaceous (Maastrichtian) Hell Creek Formation. DMNH 130952 in (1) dorsal, (2) left lateral, and (3) left medial views. Abbreviations: ang = angular; art = articular; cor = coronoid; den = dentary; $f M=$ fossa Meckelii; fna = foramen nervi auriculotemporalis; pra = prearticular; $\mathrm{sM}$ = sulcus Meckelii; sur = surangular.

contacts the descending process of the prefrontal anterodorsally and the maxilla anterolaterally to form the anterior margin of the internal nares, which is situated mid-palate. The posterior portion of the vomer broadly contacts the palatines laterally and forms a low, median ridge that subdivides the narial canals. The posterior tip of the vomer is damaged in all specimens, and it is therefore not clear whether the vomer fully subdivides the palatines, but it appears from what is preserved that the vomer nearly does so. The dorsal side of the vomer is hidden from view by crushing, as the interorbital space has collapsed in all specimens.

Palatine: The palatine is a laminar bone that floors much of the narial canal. In ventral view, the palatine anteriorly forms the posterior border of the expanded foramen orbito-nasale, laterally contacts the maxilla, posterolaterally contacts the pterygoid along a transverse suture, and medially contacts the vomer. It is unclear whether the palatine contacts its counterpart along the midline, but the expanded vomer highlights that this contact would have been relatively short, if present. A posterior contact with the basisphenoid is present in two specimens, but absent in the third (DMNH 130951). The posterior margin of the narial canal is located posterior to the posterior margin of the triturating surface. The foramen palatinum posterius is formed jointly by the palatine and the maxilla. The well-developed ascending process of the palatine contacts the descending process of the parietal dorsally, forms the anterior margin of the trigeminal foramen posteriorly, and contacts the jugal laterally behind the orbit.

Pterygoid: The pterygoid is a large element that connects the palatine to the basicranium. In ventral view the pterygoid has an elongate anterior process that contacts the maxilla anteriorly and the palatines anteromedially. The anterior process nei- ther contributes to the triturating surfaces nor to the foramen palatinum posterius. The pterygoids lack a midline contact in two specimens, but exhibit a short contact in the third (DMNH 130951). The posterior process of the pterygoid contacts the basisphenoid medially, the basioccipital posteromedially, forms the ventral floor of the confluent posterior jugular foramen and fenestra postotica, and contacts the quadrate posterolaterally just below the articular condyle. A contact with the exoccipitals is apparent above the basioccipital tubercle. The foramen posterius canalis caroticus internus is located at the back of the skull and is fully enclosed by the pterygoid. A deep pit is located just lateral to this foramen. The ascending branch of the pterygoid is obscured by crushing in all specimens, and its dorsal contacts are therefore unclear.

Epipterygoi: The trigeminal region is crushed in all three available specimens and the presence and contacts of the epipterygoid therefore cannot be assessed with confidence.

Quadrate: In lateral view, the quadrate forms the deep cavum tympani and contacts the quadratojugal anteriorly and the squamosal posteriorly and dorsally. The quadrate encloses the columella, but not the Eustachian tube, which is located in a shallow grove along the posterior margin of the quadrate. Within the upper temporal fossa, the quadrate narrowly contributes to the lateral portion of the trochlear surface, broadly contacts the prootic anteromedially, the opisthotic posteromedially, the squamosal laterally, and shortly contacts the quadratojugal anterolaterally. The relatively small stapedial foramen is located mid-length along the suture of the quadrate with the prootic. In ventral view, the quadrate forms the articular condyle, contacts the quadratojugal anteriorly, the pterygoid 
medially, and the opisthotic and pterygoid posteriorly.

Prootic: In dorsal view, the prootic broadly contacts the ascending process of the parietal anteromedially along a transverse suture, the quadrate posterolaterally, the opisthotic posteriorly, and the supraoccipital posteromedially. The prootic forms about 60 percent of the trochlear surface and forms the stapedial foramen jointly with the quadrate. The prootic also forms the dorsal margin of the trigeminal foramen, but other contacts in the region are obscured by crushing in all specimens.

Opisthotic: Within the upper temporal fossa, the opisthotic contacts the supraoccipital medially, the prootic anteriorly, and the quadrate anterolaterally. The opisthotic forms an elongate paroccipital process that broadly contacts the posterior process of the squamosal laterally. In posterior view, the opisthotic roofs the confluent posterior jugular foramen and contacts the exoccipital medially and the quadrate laterally. We cannot confirm the presence of a contact with the pterygoid as reported by Vitek (2012).

Supraoccipital: The supraoccipital forms an elongate crest that represents about 40 percent of the midline length of the skull. The crest has welldeveloped vertical and horizontal processes and is therefore T-shaped in cross-section. In dorsal view, the supraoccipital contacts the parietal anteriorly, the prootic anterolaterally, and the opisthotic laterally. The supraoccipital roofs the foramen magnum and contacts the exoccipitals lateral to this foramen.

Exoccipital: The exoccipital forms the lateral sides of the foramen magnum and contacts the supraoccipital dorsally, the basioccipital ventromedially, the pterygoid ventrolaterally, and its counterpart medially at the base of the foramen magnum. Each exoccipital forms about one-third of the occipital condyle.

Basioccipital: The basioccipital is an elongate bone that contacts the basisphenoid anteriorly, the pterygoid laterally, and the exoccipitals dorsally. The basioccipital forms the majority of the basioccipital tubercle and the central portion of the occipital condyle but the medial contact of the exoccipitals prevents the basioccipital from contributing to the foramen magnum. A broad, median depression is formed by the basioccipital and the basisphenoid.

Basisphenoid: In ventral view, the basisphenoid varies significantly among the three available specimens. It forms a stout triangle in DMNH 130951 that does not contact the palatines and/or vomer anteriorly, an elongate triangle in NSM PV24650 that contacts the palatines and/or vomer anteriorly, and an anteriorly narrowing trapezoid in DMNH 98814 that contacts the palatines and/or vomer anteriorly. In addition to the variable anterior contacts with the palatines and vomer, the basisphenoid broadly contacts the pterygoid laterally and the basioccipital posteriorly. The basisphenoid forms a rounded, median depression together with the basioccipital.

Mandible. We focus on the description of DMNH 130952 as this is the best-preserved mandible (Figure 19).

Dentary: The dentary is the largest element of the mandible. In lateral view, it contacts the coronoid and surangular posterodorsally and the articular posteriorly, and in medial view the coronoid posterodorsally and the angular posteriorly. The triturating surface is narrow medially, but broadens laterally towards the coronoid process. A median keel is missing along the symphysis.

Angular: The angular is a fragile bone that is only partially preserved. In medial view this lamellar bone contacts the articular posteriorly, the prearticular dorsally, and the dentary anteriorly. The angular likely formed the ventral margin of the poorly preserved sulcus Meckelii.

Surangular: The surangular forms the lateral half of the articular surfaces, the lateral margin of the retroarticular process, and the lateral wall of the elongate fossa Meckelii. In lateral view, it contacts the coronoid anterodorsally, the dentary anteriorly, and the articular posteroventrally. The surangular is pierced by a single foramen nervi auriculotemporalis.

Coronoid: The coronoid forms the apex of the prominent coronoid process. In lateral view, the coronoid contacts the dentary ventrally and the surangular posteriorly. In medial view the dentary contacts the prearticular posteroventrally and the dentary anteroventrally. The coronoid likely does not contribute to the sulcus Meckelii.

Articular: The articular forms the central portions of the articular surfaces and narrowly contributes to the posterior margin of the fossa Meckelii. It contacts the surangular laterally, the prearticular medially, and the angular dorsally.

Prearticular: The prearticular is poorly preserved. The posterior portion of this bone forms the medial margin of the retroarticular process, the medial wall of the fossa Meckelii, and contacts the articular posteriorly and the angular ventrally. The anterior, more lamellar portion of this bone is damaged, and it is therefore not clear how much of this bone covered the sulcus Meckelii. A well-developed antero- 
dorsal contact with the coronoid is nevertheless apparent.

Limbs, Girdles, and Vertebrae. The Big Turtle Cove locality yielded a small amount of disarticulated material pertaining to the girdles and limbs, in particular a right pelvis (Figure 9.10), a partial right scapulocoracoid (Figure 9.11), a large left and small right humerus (Figure 9.12-13), similarly sized right and left femora (Figure 9.14-15), and an ungual phalanx (Figure 9.9). This material documents the majority of currently utilized postcranial characters (Meylan, 1987). Additional, disarticulated material representing the limbs, girdles, and vertebrae were recovered from the Turtle Bonebed locality, but we were here refrain from documenting it, as most specimens are poorly preserved or poorly prepared and as this material does not document additional, phylogenetically relevant characters.

The humeri resemble those of other trionychids by having a slightly sinuous shaft, an ellipsoid caput humeri, an open ectepicondylar groove, and an elongate medial process and a short lateral process that form a wide fossa (Figure 9.12-13). The femora also resemble those of other trionychids by having a sinuous shaft, an ellipsoid caput femoris, and by possessing a slim, proximally protruding trochanter major and a short, splaying trochanter minor that form a wide intertrochanteric fossa (Figure 9.14-15).

The pelvis resembles those of other trionychids by consisting of a sutured ilium, ischium, and pubis that jointly form the acetabulum (Figure 9.10). In addition, the ilium forms a recurved shaft that does not expand distally, the lateral pubic processes are greatly expanded, an epipubic process is absent. The ischium does not protrude into the thyroid fenestra, but forms well-developed lateral processes. These ischial characters are known to be variable among trionychids (Meylan, 1987).

As in other trionychids, the scapulocoracoid is tightly sutured, and the scapular process is elongate (Figure 9.11). Damage obscures additional details.

\section{DISCUSSION}

We describe the morphology of a large sample of trionychid material from the Hell Creek and Lance formations of North Dakota, South Dakota, Montana, and Wyoming. Although complete skeletons that document firm associations between various anatomical systems are lacking, the rich, often monotypic assemblages retrieved from the Turtle Bonebed, Big Turtle Cove, Turtle Graveyard, and
Sandy Site localities allows us to make associations between skulls, carapaces and plastra with confidence.

We confirm the initial assessment of Vitek (2012) that many trionychid fossils from the Hell Creek Formation can be assigned to the Axestemys lineage based on the combined presence of large body size, more poorly developed callosities, a preneural, and a single lateral hypoplastral process. Within the Hell Creek material, we recognize two loosely defined morphotypes. The first morphotype is best exemplified by the rich material retrieved from the Turtle Bonebed locality. Specimens from this locality are smaller (carapace length no more than $45 \mathrm{~cm}$ ), but the carapacial and plastral callosities are more extensive. In particular, the nuchal callosity fully covers the underlying nuchal processes (Figure 4.2), and the hypoplastral (Figure 5.13-14) and xiphiplastral callosities (Figure 5.20-23) trace the hyoplastra/xiphiplastral junction (Figure 5.13), at least in the largest available specimens. No skull is associated with this morphotype. The second morphotype is best exemplified by the material from the Big Turtle Cove. This morphotype is notably larger than the first (carapace length up to $75 \mathrm{~cm}$ ), but the callosities are less well developed, in that the nuchal callosity does not fully cover the underlying nuchal processes (Figure 7.1) and that the hypoplastral callosity only partially frames the posterior contact with the xiphiplastron. The larger morphotype is therefore less skeletally mature than the smaller morphotype. The distinction between these two extremes is lost when material from the other localities is considered. The material from the Turtle Ridge and Turtle Graveyard sites (Figures 10, 11, 12 ), for instance, is relatively large, but has poorly developed callosities, while the largest material from the Sandy Site (Figure 16), is large and has well-developed callosities. As the two morphotypes are only supported by samples from single sites, not across the formations, we refer all material to a single, highly variable new species, Axestemys infernalis sp. nov.

Only three trionychid species that are based on type material from the Late Cretaceous (Maastrichtian) Lance Creek and Hell Creek formations are currently considered valid (Holroyd et al., 2014; Vitek and Joyce, 2015): Helopanoplia distincta Hay, 1908, Gilmoremys lancensis (Gilmore, 1916), and "Trionyx" beecheri Hay, 1904. Axestemys infernalis sp. nov. resembles Helopanoplia distincta (as described by Joyce and Lyson, 2017) by having a preneural, a netted carapacial sculpturing, 
and a single lateral hyoplastral process, but differs most obviously by being much larger, having all costal ribs end free, and by possessing less-well developed plastral callosities that do not cover the lateral hyo/hypoplastral processes and do not meet each other along the midline. Axestemys infernalis sp. nov. resembles Gilmoremys lancensis (as described by Joyce and Lyson, 2011 and Joyce et al., 2016) by having a preneural, free rib ends, and free lateral hyo/hypoplastral processes, but differs, among others, by being much larger, possessing a broad skull that lacks an extensive secondary palate, having a coarser sculpturing pattern, having more evenly sized costals, lacking longitudinal carapacial striations, lacking an anterior hyoplastral lappet (plastomenid "shoulders"), possessing a single hyoplastral process, and lacking a midline contact of the xiphiplastral callosities. Axestemys infernalis $\mathrm{sp}$. nov. finally resembles "Trionyx" beecheri (as described by Hay, 1908, pers. obs. of the holotype) by having a preneural, free rib ends, and by lacking epiplastral and entoplastral callosities, but differs by being larger, by having a coarser, netted sculpturing pattern, by having more elongate anterior epiplastral processes, lacking free lateral hyo/hypoplastral processes, and lacking a midline contact of the xiphiplastral callosities.

Although no Hell Creek material has been figured, Atoposemys superstes (Russell, 1930), Hutchemys sterea (Hutchison, 2009), and Hutchemys tetanetron (Hutchison, 2009) have been reported to occur in the Hell Creek Formation as well (Hutchison, 2009, 2013; Holroyd et al., 2014). In all cases, Axestemys infernalis sp. nov. resembles these taxa by possessing a preneural and a single lateral hyoplastral process, but differs most apparently by being substantially larger, by having an anteroposteriorly deeper nuchal callosity, by lacking an entoplastral callosity (present in $A$. superstes), and by lacking an anterior hyoplastral lappet. We therefore agree with Vitek (2012) that Axestemys infernalis sp. nov. is distinct from all other previously identified trionychid taxa from the Hell Creek Formation.

In contrast to Vitek (2012), we conclude that the Maastrichtian Axestemys infernalis sp. nov. as described herein is morphologically distinct from the late Campanian Axestemys splendidus (Hay, 1908), although a lack of explicit descriptions of the Campanian material makes comparisons difficult. In contrast to all other named species of the Axestemys lineage (see Vitek, 2012), the two Mesozoic species plesiomorphically possess carapacial and plastral callosities that are fully covered by sculpturing. Vitek (2012) noted that the Maastrichtian morph may differ from the Campanian morph by lacking a crenulated skull roof, but our expanded sample indicates that this morphology is variable in the Maastrichtian material (Figure 18). Instead, we note that the carapace of the Campanian morph is significantly wider than long (e.g., AMNH 3952 [Hay, 1908, plate 91]; TMP 1976.7.2, TMP 2001.12.27; UALVP 53250), but nearly circular in the Maastrichtian morph. This should correspond to substantial differences in the shape and dimensions of the cartilaginous flap at the back of the carapace. Considering the significant temporal gap of approximately $10 \mathrm{Ma}$ between these two populations, we expect a synthetic review of the rich available material from the late Campanian of Alberta to yield additional differences. We similarly note that the two Late Cretaceous species we recognize differ from the early Paleocene Axestemys montinsana (Vitek, 2012) by plesiomorphically possessing carapaces with sculpturing that reaches the margin of the shell, more extensive nuchal callosities, and narrower ribs. Axestemys montinsana, by contrast, resembles later representatives of the Axestemys lineage, such as Axestemys byssinus, by lacking sculpturing along the lateral margins of the carapace to create an unsculpted margin, by having more poorly formed nuchal callosities, and by having broader ribs (Vitek, 2012). Our sample of Axestemys infernalis sp. nov. leads us to believe that the lacking plastral sculpturing seen in the holotype of Axestemys montinsana may be a taphonomic artifact. It is likely that the three Campanian to early Paleocene species we recognize form an anagenetic lineage consisting of chronospecies.

Our large sample of Axestemys infernalis sp. nov. documents much shell variation consistent with ontogenetic variation apparent in other trionychids, in that larger individuals generally have better-developed shell callosities than smaller individuals. However, the fact that some of the largest individuals (e.g., from the Big Turtle Cove) possess callosities that are more poorly developed than those of smaller individuals (e.g., from the Turtle Bonebed) demands further explanation. We discuss three possible factors that may be related to variation of the shell: sexual dimorphism, habitat partitioning, and time averaging. The available sample of three similarly sized crania does not display any significant variation and we therefore do not discuss variation of the cranium.

Among extant trionychids, substantial sexual dimorphism of the shell is apparent among repre- 
sentatives of Apalone, in that females are substantially larger than males (Meylan, 1987). If applicable, larger individuals of Axestemys infernalis sp. nov. may represent female individuals, while smaller individuals may represent males. This hypothesis is supported by the relatively close phylogenetic relationships between Axestemys and Apalone (Vitek, 2012), but is contradicted by the implied accumulations of individuals of the same sex at some localities and the presence of intermediates.

The substantial size differences that exist among extant trionychid species have previously been hypothesized to represent inter-specific niche partitioning (Pritchard, 2001). Although we are unaware of any study that documents intra-specific niche partitioning for extant trionychid turtles, it is plausible that differently sized individuals of $A x e-$ stemys infernalis sp. nov. may have inhabited different regions of the available riverine habitat, with smaller individuals preferring quieter backwaters and larger individuals preferring large channels. Along these lines, the Turtle Bonebed locality may represent a backwater populated by smaller individuals of the species, while the Big Turtle Cove locality may represent a larger channel inhabited by fully grown individuals. This is broadly consistent with the sedimentological evidence, as the Turtle Bonebed locality is dominated by mudstone, while the Big Turtle Cove is dominated by sandstone. However, this hypothesis cannot account for the fact that the Turtle Bonebed locality possesses more skeletally mature specimens than those from the Big Turtle Cove locality.

As preserved, the available specimens may represent natural variation that occurred over the course of the $1.36 \mathrm{Ma}$ represented in the Hell Creek Formation (Hicks et al., 2002). Over the course of this time, representatives of the Axestemys infernalis sp. nov. lineage may have changed due to random walk, but also in response to short term (i.e., generational) climatic changes, such as prolonged periods with optimal versus non-optimal growing conditions. Under this scenario, the smaller turtles preserved at the Turtle Bonebed locality may represent more slowly growing individual that lived under stressed climatic conditions, while the larger turtles preserved at the Big Turtle Cove may represent individuals that flourished under ideal conditions. Although we cannot discount possible contributions from sexual dimorphism and ontogenetic niche partitioning, this model is best supported by the available data, as it also accounts for intermediate morphologies.

\section{ACKNOWLEDGEMENTS}

We wish to thank $C$. Mehling (AMNH), M. Walsh (LACM), and A. Farke (RAM) for providing us with photographs of specimens in their care. We thank M. Stewart, A. Glasgow, N.e Toth, and S. Bastien for preparation, R. Wicker for photography, and K. MacKenzie (all at DMNS) for access to collections. L. Wilson (FHSM), M. Manabe (NSM), and C. Sakata (NSM) are thanked for their hospitality while visiting collections. P. Meylan and two anonymous reviewers are thanked for numerous insightful comments that greatly helped improve the quality of this manuscript. A. Souron is thanked for careful editing. This project was partially funded by a grant by the Swiss National Science Foundation to WGJ (SNF 200021_153502).

\section{REFERENCES}

Bartlett, J.A. 2004. Taphonomy, Geology, and Paleoecology of the Sandy Site, an Exceptional Asemblage in the Maastrichtian Hell Creek Formation of South Dakota. MS Thesis, North Carolina State University, USA.

Batsch, A.J.G.C. 1788. Versuch einer Anleitung, zur Kenntniß und Geschichte der Thiere und Mineralien. Akademische Buchhandlung, Jena. https://doi.org/10.5962/bhl.title.79854

Case, E.C. 1939. A nearly complete turtle skeleton from the Upper Cretaceous of Montana. Contributions from the Museum of Paleontology, University of Michigan, 6:1-19.

Cope, E.D. 1868. On the origin of genera. Proceedings of the Academy of Natural Sciences of Philadelphia, 20:242-300.

Cope, E.D. 1874. Review of the Vertebrata of the Cretaceous period found west of the Mississippi River. Bulletin of the United States Geological and Geographical Survey, 2:5-48. https://doi.org/10.3133/70159426 
Gaffney, E.S. 1972. The systematics of the North American family Baenidae (Reptilia, Cryptodira). Bulletin of the American Museum of Natural History, 147:241-320.

Gardner, J.D. and Russell, A.P. 1994. Carapacial variation among soft-shelled turtles (Testudines: Trionychidae), and its relevance to taxonomic and systematic studies of fossil taxa. Neues Jahrbuch für Geologie und Paläontologie, Abhandlungen, 193:209-244.

Gilmore, C.W. 1916. Description of two new species of fossil turtles, from the Lance Formation of Wyoming. Proceedings of the United States National Museum, 50:641-646. https://doi.org/ 10.5479/si.00963801.50-2137.641

Gray, J.E. 1825. A synopsis of the genera of reptiles and amphibia, with a description of some new species. Annals of Philosophy, 10:193-217.

Hay, O.P. 1899. On the nomenclature of certain American fossil vertebrates. American Geologist, 24:345-349.

Hay, O.P. 1904. On some fossil turtles belonging to the Marsh collection in Yale University Museum. American Journal of Science, 18:261-276. https://doi.org/10.2475/ajs.s418.106.261

Hay, O.P. 1908. The Fossil turtles of North America. Carnegie Institution of Washington Publication, 75:1-568. https://doi.org/10.5962/bhl.title.12500

Hicks, J.F., Johnson, K.R., Obradovich, J.D., Tauxe, L., and Clark, D. 2002. Magnetostratigraphy and geochronology of the Hell Creek and basal Fort Union Formations of southwestern North Dakota and a recalibration of the age of the Cretaceous-Tertiary boundary. Geological Society of America Special Paper, 361:57-74. https://doi.org/10.1130/0-8137-2361-2.35

Holroyd, P.A and Hutchison, J.H. 2002. Patterns of geographic variation in the latest Cretaceous vertebrates: evidence from the turtle component. Geological Society of America Special Paper, 361:177-190. https://doi.org/10.1130/0-8137-2361-2.177

Holroyd, P.A., Wilson, G.P., and Hutchison, J.H. 2014. Temporal changes within the latest Cretaceous and early Paleogene turtle faunas of northeastern Montana. Geological Society of America Special Paper, 503:299-312. https://doi.org/10.1130/2014.2503(11)

Hutchison, J.H. 2009. New soft-shelled turtles (Plastomeninae, Trionychidae, Testudines) from the Late Cretaceous and Paleocene of North America. PaleoBios, 29:36-47.

Hutchison, J.H. 2013. New turtles from the Paleogene of North America, p. 477-497. In Brinkman, D.B., Holroyd, P.A., and Gardner, J.D. (eds.), Morphology and Evolution of Turtles. Springer Verlag, Dordrecht. https://doi.org/10.1007/978-94-007-4309-0_26

Hutchison, J.H. and Archibald, J.D. 1986. Diversity of turtles across the Cretaceous/Tertiary boundary in northeastern Montana. Palaeogeography, Palaeoclimatology, Palaeoecology, 55:1-22. https://doi.org/10.1016/0031-0182(86)90133-1

Joyce, W.G. and Lyson, T.R. 2011. New material of Gilmoremys lancensis nov. comb. (Testudines: Trionychidae) from the Hell Creek Formation and the diagnosis of plastomenid turtles. Journal of Palaeontology, 85:444-461. https://doi.org/10.1666/10-127.1

Joyce, W.G. and Lyson, T.R. 2017. The shell morphology of the latest Cretaceous (Maastrichtian) trionychid turtle Helopanoplia distincta. PeerJ, 4:e4169. https://doi.org/10.7717/peerj.4169

Joyce, W.G., Lyson, T.R., and Williams, S. 2016. New cranial material of Gilmoremys lancensis (Testudines, Trionychidae) from the Hell Creek Formation of southeastern Montana, USA. Journal of Vertebrate Paleontology, e1225748. https://doi.org/10.1080/ 02724634.2016 .1225748

Knauss, G.E., Joyce, W.G., Lyson, T.R., and Pearson, D. 2011. A new kinosternoid from the Late Cretaceous Hell Creek Formation of North Dakota and Montana and the origin of the Dermatemys mawii lineage. Paläontologische Zeitschrift, 85:125-142. https://doi.org/ 10.1007/s12542-010-0081-x

Leidy, J. 1856. Notices of the remains of extinct reptiles and fishes discovered by Dr. F.V. Hayden in the bad lands of the Judith River, Nebraska Territory. Proceedings of the Academy of Natural Sciences of Philadelphia, 8:72-73.

Lyson, T.R. and Joyce, W.G. 2009a. A new species of Palatobaena (Testudines: Baenidae) and a maximum parsimony and Bayesian phylogenetic analysis of Baenidae. Journal of Paleontology, 83:457-470. https://doi.org/10.1666/08-172.1

Lyson, T.R. and Joyce W.G. 2009b. A revision of Plesiobaena (Testudines: Baenidae) and an assessment of baenid ecology across the K/T boundary. Journal of Paleontology, 83:833853. https://doi.org/10.1666/09-035.1 
Lyson, T.R. and Joyce, W.G. 2010. A new baenid turtle from the Late Cretaceous (Maastrichtian) Hell Creek Formation of North Dakota and a preliminary taxonomic revision of Cretaceous Baenidae. Journal of Vertebrate Paleontology, 30:394-402. https://doi.org/10.1080/ 02724631003618389

Lyson, T.R. and Joyce, W.G. 2011. Cranial anatomy and phylogenetic placement of the enigmatic turtle Compsemys victa. Journal of Paleontology, 85:789-801. https://doi.org/10.1666/10081.1

Lyson, T.R., Joyce, W.G., Knauss, G., and Pearson, D. 2011. Boremys (Testudines: Baenidae) from the latest Cretaceous and early Paleocene of North Dakota: an 11 million year range extension and an additional K/T survivor. Journal of Vertebrate Paleontology, 31:1-9. https:// doi.org/10.1080/02724634.2011.576731

Meylan, P.A. 1987. The phylogenetic relationships of softshelled turtles (family Trionychidae). Bulletin of the American Museum of Natural History, 186:1-101.

Meylan, P.A. and Gaffney, E.S. 1989. The skeletal morphology of the Cretaceous cryptodiran turtle, Adocus, and the relationships of the Trionychoidea. American Museum Novitates, 2941:1-60.

Nopcsa, F. 1928. The genera of reptiles. Palaeobiologica, 1:163-188.

Pritchard, P.C.H. 2001. Observations on body size, sympatry, and niche divergence in softshell turtles (Trionychidae). Chelonian Conservation and Biology, 4:5-27.

Riggs, E.S. 1906. The carapace and plastron of Basilemys sinuosus, a new fossil tortoise from the Laramie Beds of Montana. Field Columbian Museum, Geological Series 2:249-256. https://doi.org/10.5962/bhl.title.3563

Rollot, Y., Lyson, T.R., and Joyce, W.G. 2018. A description of the skull of Eubaena cephalica (Hay, 1904) and new insights into the cranial circulation and innervation of baenid turtles. Journal of Vertebrate Paleontology, e1474886. https://doi.org/10.1080/ 02724634.2018.1474886

Russell, L.S. 1930. A new species of Aspideretes from the Paskapoo Formation of Alberta. American Journal of Science, 20:27-32. https://doi.org/10.2475/ajs.s5-20.115.27

Russell, D.A. and Manabe, M. 2002. Synopsis of the Hell Creek (uppermost Cretaceous) dinosaur assemblage. Geological Society of America Special Paper, 361:169-176. https:// doi.org/10.1130/0-8137-2361-2.169

Triebold, M. 1997. The Sandy site: small dinosaurs from the Hell Creek Formation of South Dakota, p. 245-248. In Wolberg, D., Stump, E., and Rosenberg, G. (eds.), Dinofest International: Proceedings of a Symposium. Arizona State University, Tempe and Academy of Natural Science, Philadelphia.

Vitek, N.S. 2012. Giant fossil soft-shelled turtles of North America. Palaeontologia Electronica, 15.1.13A:1-43. https://doi.org/10.26879/299 palaeo-electronica.org/content/2012-issue-1-articles/210-giant-soft-shelled-turtles

Vitek, N.S. and Joyce, W.G. 2015. A review of the fossil record of turtles of the clade PanTrionychidae. Bulletin of the Peabody Museum of Natural History, 56:185-244. https://doi.org/ 10.3374/014.056.0204

Whetstone, K.N. 1978. A new genus of cryptodiran turtles (Testudinoidea, Chelydridae) from the Upper Cretaceous Hell Creek Formation of Montana. University of Kansas Science Bulletin, 51:539-563. https://doi.org/10.5962/bhl.part.17248 